\title{
From Decades to Epochs: Spanning the Gap Between Geodesy and Structural Geology of Active Mountain Belts
}

Richard W. Allmendinger

Cornell University

John P. Loveless

HarvardUniversity, jloveles@smith.edu

Matthew E. Pritchard

Cornell University

Brendan Meade

Harvard University

Follow this and additional works at: https://scholarworks.smith.edu/geo_facpubs

Part of the Geology Commons

\section{Recommended Citation}

Allmendinger, Richard W.; Loveless, John P.; Pritchard, Matthew E.; and Meade, Brendan, "From Decades to Epochs: Spanning the Gap Between Geodesy and Structural Geology of Active Mountain Belts" (2009). Geosciences: Faculty Publications, Smith College, Northampton, MA.

https://scholarworks.smith.edu/geo_facpubs/19

This Article has been accepted for inclusion in Geosciences: Faculty Publications by an authorized administrator of Smith ScholarWorks. For more information, please contact scholarworks@smith.edu 


\section{From decades to epochs: Spanning the gap between geodesy and structural geology of active mountain belts} 21 rich new data to mine by providing denser, more uniform, and temporally continu ous

22 observations.

\section{Richard W. Allmendinger ${ }^{1}$, John P. Loveless ${ }^{2}$, Matthew E. Pritchard ${ }^{1}$, Brendan Meade ${ }^{2}$}

${ }^{1}$ Dept. of Earth \& Atmospheric Sciences Cornell University, Ithaca, NY 14853-1504

${ }^{2}$ Dept. of Earth \& Planetary Sciences, Harvard University, Cambridge, MA

\section{Abstract}

Geodetic data from the Global Navigation Satellite System (GNSS), and from satellite interferometric radar (InSAR) are revolutionizing how we look at instantaneou s tectonic deformation, but the significance for long-term finite strain in orogenic belts is less clear. We review two different ways of analyzing geodetic data: velocity gradient fields from which one can extract strain, dilatation, and rotation rate, and elastic block modeling, which assumes that deformation is not continuous but occurs primarily on networks of interconnected faults separating quasi-rigid blocks. These methods are complementary: velocity gradients are purely kinematic and yield information about regional deformation; the calculation does not take into account either faults or rigid blocks but, where GNSS data are dense enough, active fault zones and stable blocks emerge naturally in the solution. Block modeling integrates known structural geometry with idealized earthquake cycle models to predict slip rates on active faults. Future technological advances should overcome many of today's uncertainties and provide 


\section{Introduction}

Structural geologists have always wanted to study the growth of structures in real time: how do limbs of folds rotate? How do fault damage zones evolve? How do extensional detachments and thrust belt décollements work? A myriad of additional

27 questions could be asked about different structural processes. Most structural geology involves the interpretation of process from the finite strain at the end point of the deformation. Clever methods, ranging from growth strata geometries to curved fibrous minerals in pressure shadows and veins, and sophisticated numerical mechanical and

31 kinematic models have been developed to try to extract interpretations of incremental 32 strains and insight into processes.

Today, we can sample in real time the surface effects of on-going structural processes via space-based geodesy. This ability, seemingly, should bring uniformitarianism to structural geology: the processes that we observe in action today should be the same as those that were responsible for the older structures that we see exposed in mountain belts. However, despite two decades of the widespread availability of Global Positioning System (GPS) and Interferometric Synthetic Aperture Radar (InSAR) geodetic data, such information is still relatively little used in the structural geology community. Two fundamental reasons underlie the gulf between traditional structural ge-

41 ology and geodesy, both related to the fact that much of the geodetic signal we observe

42 is related to the earthquake cycle: First, a significant part of that deformation is elastic.

43 We still need to understand the relationship between this non-permanent, infinitesimal 44 strain and permanent, finite strain with which structural geologists are more familiar. 45 Second, we have just two decades (or less) of space geodesy, but the earthquake cycle on plate boundaries lasts on the order of 100-200 years and in continental interiors can

47 be more than 1000 years. Thus, we are trying to understand a finite process - ultimate- 
ly, mountain building - by sampling just $1 / 10$ th to one $1 / 100$ th of the smallest signifi-

49 cant unit of that process (i.e., the earthquake cycle).

In this paper, we review what has been learned to date about the relationship be-

51 tween geodetic and structural geology observations. We examine the most common

52 analytical methods currently used (calculation of velocity gradient fields and elastic

53 block modeling) and the issues and artifacts surrounding those methods. For both of

54 these methods, questions about spatial scaling and continuous (or discontinuous) na-

55 ture of surface deformation are key. Current advances in understanding of earthquake

56 and volcanic processes, as well as regional tectonics, underscore the utility of working

57 with geodetic data from a geological viewpoint. Finally, we examine how new technol-

58 ogy will further enhance our ability to use these data.

\section{2. The Nature of Space Geodesy Data}

60 For more than 100 years, repeat surveys of geodetic monuments have revealed 61 the deformation of the Earth's surface from tectonic processes (e.g., Yeats et al., 1997).

62 The advent of space-based geodetic measurements has allowed these surveys to be 63 done more frequently, more densely, more precisely, and over larger areas of the world.

\section{2.1. Global Navigation Satellite System}

The most commonly and widely used space-based technique (at least in terms of number of papers published) relies upon the establishment of a geodetic station and an-

67 tenna that can receive signals simultaneously from several satellites in a global constel-

68 lation. The constellation is commonly referred to as the Global Positioning System

69 (GPS), but is now more generally termed the Global Navigation Satellite System (GNSS)

70 because it includes the original GPS satellites as well as satellites from the European Ga-

71 lileo and the Russian GLONASS constellations, and may include others in the future

72 (Hofmann-Wellenhof et al., 2008). 
The GNSS observations are often divided into two end members: campaign ob-

74 servations that involve occupation of a geodetic benchmark for a few hours or days 75 every year or so, and continuous stations that are not moved around and take a mea76 surement as frequently as 10 times a second (e.g., Larson et al., 2003). The majority of

77 published results to date report campaign data in which errors in vertical velocity 78 typically three to five times greater than errors in the horizontal - are so large as to 79 render them unusable (Segall and Davis, 1997). Thus campaign data usually provide 80 only a two dimensional velocity field and, because of their intermittent nature, cannot 81 capture short term transient deformation events nor fully describe the potentially signif82 icant annual or quasi-seasonal component of the deformation field, points to which we 83 return in a later part of the paper. Continuous GNSS observations avoid both of these 84 drawbacks yet still reflect velocities determined at a relatively small number of discrete 85 stations rather than more spatially continuous velocity fields.

\subsection{Interferometric Synthetic Aperture Radar}

Satellite-based Interferometric Synthetic Aperture Radar (In SAR) has greatly expanded the spatial and temporal coverage of ground deformation (e.g., Bürgmann et al.,

89 2000a; Rosen et al., 2000). InSAR is capable of measuring deformation of the Earth's sur-

90 face with a pixel spacing of order 1-10 meters over hundreds of kilometers. Accuracy on

91 the order of $1 \mathrm{~mm} / \mathrm{yr}$ can be obtained when many overlapping observations are com-

92 bined in order to create a time series, or when stable ground points can be identified

93 (e.g., persistent or permanent scatters or PSInSAR, Berardino et al., 2002; Ferretti et al., 94 2001; Hooper et al., 2004). An additional advantage of InSAR is that measurements can 95 be made during every satellite overflight (weeks to months apart) without laborious 96 ground surveys. In contrast to GNSS data, InSAR can provide more spatially complete 97 velocity fields, however the measurement obtained is only of the component of the total 98 velocity vector in the look direction of the satellite. That is, a single interferogram meas- 
ures ground displacements that occur along the line of sight between the satellite and

100 the ground - meaning that multiple interferograms with different lines of sight are ne101 cessary to reconstruct the three-dimensional ground motion (e.g., Fialko et al., 2005).

102 Furthermore, the frame of reference is local and corresponds only to the region over 103 which the radar signal is coherent.

104 2.3. Effects of incomplete temporal sampling

Space geodetic observations may be affected by a variety of non-tectonic

106 processes including changes in the atmosphere the electromagnetic signals travel 107 through, monument instability (due to thermal effects, soil creep, etc.) and real ground 108 movements from hydrological or anthropogenic sources (e.g., Segall and Davis, 1997). 109 Often these later types of deformation vary seasonally, for example, subsidence during 110 a dry season when sub-surface groundwater reservoirs are depleted or recharged dur111 ing a wet season (Reilinger and Brown, 1981; Schmidt and Bürgmann, 2003) or dow n112 ward flexure of the crust under a snow load during the winter (e.g., Heki, 2001; Blew itt 113 et al., 2001). The deformation pattern may vary in amplitude from year to year and does 114 not usually follow a simple seasonal (or sinusoidal) pattern due to other contributions, 115 and so is often called quasi-seasonal. Such quasi-seasonal patterns are routinely re116 moved from continuous GPS observations or when InSAR data or other ancillary in117 formation, is available (e.g., Bawden et al., 2001; Argus et al., 2005).

\section{3. Strain rate from velocity fields}

\section{3.1. Strain at a point from three or more stations}

120 The simplest way to analyze deformation from inherently kinematic geodetic da121 ta, and that which is most comfortable to many structural geologists, is to calculate gra122 dients in the velocity field (Allmendinger et al., 2007; Cardozo and Allmendinger, 2008).

123 The pertinent equation is well known to structural geologists, though many are more 
124 familiar with the non-time derivative format in which $D_{i j}$ would be the displacement 125 gradient tensor:

$$
u_{i}=t_{i}+\frac{\partial u_{i}}{\partial x_{j}} x_{j}=t_{i}+D_{i j} x_{j}
$$

127 where $u_{i}$ is the velocity at a station, $D_{i j}$ is the asymmetric velocity gradient tensor, $x_{j}$ 128 are the coordinates of the station, and $t_{i}$ is a constant of integration representing the ve129 locity of a point at the origin of the coord inate system. Because geodetic strain is most 130 assuredly infinitesimal, it does not matter whether the initial or final station coordinates 131 are used; technically the symmetric part of $D_{i j}$ is the rate of deformation tensor with re132 spect to the final coordinates and the time derivative of the strain tensor if initial coor133 dinates are used (e.g., Malvern, 1969). In three dimensions, equation (1) represents a 134 system of three equations ( $i, j=1$ to 3 ) with 12 unknowns: the 9 components of $D_{i j}$ and 135 the three components of $t_{i}$. Because there are three equations for each station (corres136 ponding to the east, north, and elevation components of the velocity vector and station 137 coordinates), the solution for the unknowns is exactly constrained for four non-coplanar 138 stations; for two-dimensional data, more commonly the case with GPS data, 3 non139 colinear stations are required to solve for the four components of $D_{i j}$ and two of $t_{i}$ (as 140 shown graphically in Fig. 1). We rewrite the system of equations to isolate the un141 knowns (in two dimensions): 


$$
\mathbf{d}=\left[\begin{array}{c}
{ }^{1} u_{1} \\
{ }^{1} u_{2} \\
{ }^{2} u_{1} \\
{ }^{2} u_{2} \\
\cdots \\
\cdots \\
{ }^{n} u_{1} \\
{ }^{n} u_{2}
\end{array}\right]=\left[\begin{array}{cccccc}
1 & 0 & { }^{1} x_{1} & { }^{1} x_{2} & 0 & 0 \\
0 & 1 & 0 & 0 & { }^{1} x_{1} & { }^{1} x_{2} \\
1 & 0 & { }^{2} x_{1} & { }^{2} x_{2} & 0 & 0 \\
0 & 1 & 0 & 0 & { }^{2} x_{1} & { }^{2} x_{2} \\
\ldots & \ldots & \ldots & \ldots & \cdots & \cdots \\
\cdots & \cdots & \cdots & \cdots & \cdots & \cdots \\
1 & 0 & { }^{n} x_{1} & { }^{n} x_{2} & 0 & 0 \\
0 & 1 & 0 & 0 & { }^{n} x_{1} & { }^{n} x_{2}
\end{array}\right]\left[\begin{array}{c}
t_{1} \\
t_{2} \\
D_{11} \\
D_{12} \\
D_{21} \\
D_{22}
\end{array}\right]=\mathbf{G m}
$$

143 We can solve for the matrix of unknowns, m (the $t_{i}$ plus the components of the velocity 144 gradient tensor), in the over-constrained case (i.e., $n>3$ ) by standard least squares ma145 trix inversion (Menke, 1984):

$$
\mathbf{m}=\left[\mathbf{G}^{\mathrm{T}} \mathbf{G}\right]^{-1} \mathbf{G}^{\mathrm{T}} \mathbf{d}
$$

147 Alternatively, equation (2) can be solved for $\mathbf{m}$ with a weighted least squares inversion 148 (Menke, 1984):

$$
\mathbf{m}=\left[\mathbf{G}^{\mathrm{T}} \mathbf{W G}\right]^{-1} \mathbf{G}^{\mathrm{T}} \mathbf{W d}
$$

150 where $\mathbf{W}$ is the diagonalized matrix of weighting values, W. Equation (4) allows us to 151 weight the contribution of each station used according to its distance from the point 152 where the calculation is made (Shen et al., 1996),

$$
W=\exp \left(\frac{-d^{2}}{2 \alpha^{2}}\right)
$$


154 where $\alpha$ is a smoothing constant that specifies how the effect of a particular station de155 cays with distance from the point of the calculation.

Once the velocity gradient tensor has been calculated, it may be additively de157 composed into a symmetric strain rate and antisymmetric rotation rate tensors. For infi158 nitesimal deformation, the first invariant of the strain rate tensor is the dilatation, or vo159 lume strain, rate of the region. Where GNSS data are two-dimensional, the full dilata160 tion rate cannot be determined, but the 2D dilatation rate contains considerable infor161 mation of interest (Allmendinger et al., 2007). Likew ise, only a vertical axis rotation rate 162 can be determined in two dimensions.

\section{3.2. Spatial Variation in Strain Rate}

164 Of course, calculating a single strain rate from an arbitrary selection of stations 165 assumes that strain is homogenous and is less useful than seeing how strain rate varies

166 spatially across large areas and especially across structures of interest. In general, a rec167 tangular grid or Delaunay triangulation using the actual GPS stations as nodes is con168 structed across the region of interest. If one starts with velocities and calculates strain 169 rates, there is always a realistic solution, especially where the displacements over the 170 time period of measurement are small compared to the station spacing. However, if one 171 starts with strain rate data and calculates velocities, then St.-Venant's compatibility eq172 uations must be satisfied to make sure that the strain is compatible (Malvern, 1969; 173 Haines and Holt, 1993; Holt et al., 2000). The Global Strain Rate Map (Kreemer et al., 1742003 ) is an example of the application of this theory utilizing strain rates inferred from 175 from earthquake moment tensor solutions, and Quaternary fault-slip rate data com176 bined with GNSS data.

177 Once a grid has been defined, there are two simple approaches to calculating 178 strain and rotation rate at each node. In the nearest neighbors method, only the $n$ sta179 tions nearest to the grid node are used in the calculation of strain at the node. Because 
stations are not typically distributed uniformly across the region of interest, this ap-

181 proach has the effect of a spatially varying length scale, as described, below. Alterna-

182 tively, one can use the distance weighted method of Shen et al. (1996) where the strain

183 rate at each node is calculated from all of the GNSS vectors in the data set, but the con-

184 tribution of each vector is weighted by its distance from the node. The weighting factor,

$185 \alpha$, in equation (5) provides a means of smoothing the strain rate field at different wave186 lengths.

\section{3.3. Length scale and irregular station spacing/distribution}

The pitfalls of inverting GNSS vectors for strain rate should be familiar to structural geologists: they involve the inherent length scale dependence of strain and artifacts that can arise from the fact that our observations are not regularly spaced but are

191 clustered in some areas relative to others. None of this would matter if the strain rate

192 were homogeneous across the region of interest, but it is profoundly heterogeneous at 193 both the finite deformation scale and the geodetically infinitesimal scale (Fig. 1). When 194 calculating the shear strain across a broad shear zone, the result depends on where the 195 measurements are made (Ramsay and Graham, 1970) and two transects across the shear 196 zone will yield quite different results if the measurements on one transect are clustered 197 near the center of the zone and in the other are taken far from the center. In the example 198 shown in Figure 1, the magnitude of strain and orientation of principal axes would be 199 different if the three stations were closer to the fault (higher strain) or farther away from 200 the fault. The same is true for GNSS data and we illustrate this with an interesting and 201 potentially significant case from the Himalayan front.

202 The Himalayan front is well known for generating a number of large, damaging 203 earthquakes (Bilham et al., 2001; Bilham, 2006). In northwestern India, the $\sim 150 \mathrm{~km}$ on 204 either side of the Dehra Dun recess in the Main Boundary thrust have not slipped since 2051400 A.D. (Banerjee and Bürgmann, 2002; Kumar et al., 2006). Except for a short stretch 
206 in Bhutan, this segment is the longest-lived seismic gap along the entire Himalayan 207 front, and thus presents considerable potential seismic hazard. Analysis of the comp o208 site GPS data set from Zhang et al. (2004) using a nearest neighbor analysis produces a 209 pronounced shortening rate anomaly in the middle of the seismic gap (Fig. 2a): the 210 principal horizontal shortening rate (which has a negative sign) there is about twice that 211 on either side of the gap. Because our temporal sampling interval is much less than the 212 earthquake cycle, a common strategy is to use along strike variation as a proxy for time; 213 thus, it is tempting to interpret this anomaly as possible evidence of impending rupture 214 on this segment, the anomaly is more likely due to the dense cluster of GPS stations 215 (Banerjee and Bürgmann, 2002) in the recess. If we subsample the GPS stations down to 216 a density and distribution more nearly similar to that elsewhere along the front, the 217 anomaly disappears (Fig. 2b); it also disappears when the distance weighted algorithm 218 is used (Allmendinger et al., 2007).

219 The conclusion that the shortening rate anomaly is probably an artifact of station 220 density does not necessarily mean that this seismic gap is quiescent and unlikely to ex221 perience a large earthquake in the near future. The rate of strain accumulation on a 222 locked fault segment may be relatively constant throughout the interseismic period and 223 should be assessed from the point of view of dislocation modeling. In the much more 224 densely sampled eastern margin of Tibet, no strain rate anomaly was observed in data 225 collected in the decade prior to the Sichuan earthquake of 2008 (Fig. 3). However, in that 226 area, the network consists of campaign stations and, continuous observations might be 227 necessary to capture any pre-seismic anomalies, if they existed at all.

228 We illustrate the effect of length scale by two different calculations of two229 dimensional dilatation rate of continuous GNSS data from the Plate Boundary Observa230 tory (PBO) for the western United States (UNAVCO, 2008). If deformation is constant 231 volume, then the $2 \mathrm{D}$ dilatation rate should be positive where excess horizontal exten- 
232 sion rate occurs, implying a region of crustal thinning, and negative where there is an 233 excess of horizontal shortening rate, suggesting a region of crustal thickening (Allmen234 dinger et al., 2007). These regional patterns are very well developed when the PBO data 235 are analyzed using the distance weighted algorithm with a smoothing distance, $\alpha=100$ $236 \mathrm{~km}$, appropriate to the scale of the tectonic province (Fig. 4a). The choice of $\alpha$ depends 237 both on the spacing of the GNSS network and the scale of the problem of interest and 238 thus will vary from province to province and network to network. The Basin and Range 239 is a province of crustal thinning on both finite and infinitesimal scales, whereas Casca240 dia, dominated by an active subduction zone, is an area of crustal thickening produced 241 by interseismic locking of the plate boundary.

A completely different, but equally valid, picture of the western United States 243 emerges when a nearest neighbor analysis is applied (Fig. 4b). As emphasized above, 244 clusters of stations can produce apparent strain rate anomalies, but they can also high245 light real zones of rapid strain rate. When the PBO data are analyzed using twelve near246 est neighbors, the areas that emerge are largely on es of active volcanic deformation 247 Mt. St. Helens, the Long Valley Caldera, and Yellowstone - and to a lesser extent the 248 San Andreas fault and Mendocino Triple Junction. For the volcanic centers, the defor249 mation reflects inflation or deflation of the underlying magma chambers so the assum p250 tion of constant volume does not hold. Notice, too, that there is a factor of 40 difference 251 in the magnitudes of strain that are calculated from exactly the same data set. The dif252 ference, fundamentally, is the length scale over which the calculation is made.

\section{4. Block modeling}

254 In addition to assessing the deformation recorded by geodetic data using the ve255 locity gradient method, several classes of quantitative models have been used to interp256 ret deformation measured by geodesy, namely continuum, microplate, earthquake 257 cycle, and block models. These methods have been described and compared in previous 
258 review papers (e.g., Thatcher, 1995; Thatcher, 2009; Thatcher, 2003; Meade and Loveless, 259 2009) but we comment here specifically on the bearing these models have on geodetic 260 and geologic observations.

261 Continuum models assume that crustal deformation can be effectively 262 represented as smoothly varying (e.g., England and Molnar, 2005; Haines and Holt, 263 1993). The "thin viscous sheet" parameterization of bulk lithospheric rheology allows 264 for the linear estimation of crustal strain rates resulting from applied forces (e.g., Eng265 land and McKenzie, 1982). Microplate models of continental deformation (e.g., Avouac 266 and Tapponnier, 1993; Thatcher, 2007) adopt the kinematic description of motion cen267 tral to plate tectonic theory, describing geodetically determined velocities as resulting 268 exclusively from the rotation of crustal blocks about Euler poles. By nature, such motion 269 is discontinuous across block boundaries. Continuum and microplate models have been 270 considered to lie at opposite ends of a spectrum of crustal deformation hypotheses 271 (Thatcher, 1995), with the latter assuming that measured deformation is accommodated 272 on a relatively small number of major crustal structures. The continuum limit approx273 imates a pervasively fractured upper crust with deformation accommodated on an infi274 nite number of faults. Therefore, continuum models do not provide information regard275 ing slip rates on specific geologic structures. Earthquake cycle models (Savage and Bur276 ford, 1973; Savage, 1983), which are commonly used to model inter-, co-, and/ or post277 seismic deformation around individual or small groups of structures, rely on disloca278 tion theory to describe the accumulation and release of elastic strain near faults. Block 279 theory combines microplate and earthquake cycle models, describing interseismic geo280 detic velocities as the summed effects of crustal block rotation and the earthquake cycle 281 processes that occur on the faults defining block boundaries (Matsu'ura et al., 1986; 282 McCaffrey, 2002; Meade and Hager, 2005; Meade and Loveless, 2009). By integrating 283 seismic cycle models with micro-plate rotations, block models provide information 
284 about relative motion across discrete structures as well as the smooth velocity gradients 285 produced by the accumulation of elastic strain on these structures.

In microplate and block models, the geometry of the crustal blocks is generally 287 inferred from maps of plate boundaries and active faults. The entire area of interest is 288 discretized into a netw ork of contiguous faults that intersect to define the boundaries of 289 blocks. Generating a block geometry from an active fault map thus requires connection 290 of structures that have been mapped as, and may in fact be, discontinuous (e.g., en 291 echelon faults, tip line folds, etc.) and assumptions regarding fault intersections. Addi292 tionally, it may be impractical to incorporate all active faults into a block model given 293 the distribution of GPS stations, as closely spaced faults may produce deformation sig294 nals that are difficult to identify uniquely. These compromises are well understood by 295 practitioners as artifacts of the current state of the modeling procedure. For example, 296 fault terminations within a block result in unbounded stresses at the tip line in most dis297 location theory (leading some to explore fractal approaches, King, 1983), even though 298 fault tip lines certainly exist in nature. Dense InSAR observations could be combined 299 with the GPS observations to test the existence of closely spaced faults in a block model, 300 but this has not yet been done (although see Fialko, 2006 for an example of how InSAR 301 contributes to estimates of fault slip rates even in areas with dense GPS).

302 Quantitatively, the frequency distribution of both geodetically and geologically 303 constrained fault slip rates in southern California suggest that $97 \%$ of the deformation 304 between the Pacific and North American plates is accommodated on faults slipping $\geq 1$ $305 \mathrm{~mm} / \mathrm{yr}$ (Meade, 2007). Considering only these faults significant in a block model means 306 that the accumulated effects of faults slipping more slowly are aliased or mapped onto 307 the faster-slipping, modeled structures (Meade, 2007). Thus the general question "How 308 many blocks are necessary?" can be quantitatively stated as "How many blocks are ne309 cessary to model deformation in a particular region at a given level of precision?" wh ich 
310 can be determined through the testing of multiple fault system geometries. Structural

311 geologists make much the same supposition when they construct a balanced cross sec-

312 tion because the implicit assumption is that that the deformation due to faulting, and to

313 a much lesser extent folding, can be largely accounted for by a relatively small number

314 of thrust faults (Marrett and Allmendinger, 1990; Marrett and Allmendinger, 1991; Mar-

315 rett and Allmendinger, 1992).

316 Basing a block model geometry on an active fault map facilitates comparison be-

317 tween the geodetically constrained slip estimates from the model and information about

318 the long-term motion on faults generally provided by paleoseismological or geological

319 data. Of course, temporal variations in fault activity can hinder the comparison of geo-

320 logic and geodetic slip rates, because the latter can be estimated only on those faults

321 that are active, literally, during the deployment of the geodetic network. However,

322 these discrepancies provide an opportunity to und erstand better temporal variations in

323 fault system behavior. Even if only the sense, but not rate, of long-term slip is known

324 for a particular structure, it provides valuable information against which the block

325 model results can be compared. At the same time, block models are capable of making

326 predictions about the structural characteristics everywhere in a plate boundary zone,

327 including regions where the model may be a poor description of faulting. In particular,

328 localized groups of coherent residual velocity vectors may suggest the presence of a

329 previously unknown structure, or anomalous behavior, such as interseismic creep or

330 partial coupling. Block models thus can be particularly useful in remote regions, such as

331 rugged and/ or forested mountains and areas offshore, where the distribution of active

332 faults is likely to be less well known. Additionally, the coupling of fault slip rates and

333 rotational motions in the classic block model formulation implicitly predicts the prop a-

334 gated consequences of changing a single slip rate throughout the entire fault network. 


\section{Lessons learned}

In the last decade, several significant earthquakes have been captured by GNSS and/ or InSAR data (e.g., Fielding et al., 2005; Klotz et al., 1999; Pritchard et al., 2002;

338 Reilinger et al., 2000; Simons et al., 2002). All of these studies demonstrate unequivocal339 ly that elastic strain accumulation and release is the dominant signal in geodetic data.

\subsection{Interseismic deformation and permanent strain}

At a regional scale within continents, interseismic deformation is most nearly 342 similar to regional late Cenozoic tectonic deformation (compare the strain in Figure $1 \mathrm{~b}$ 343 and c). This is particularly true for orientation but also, somewhat surprisingly, for 344 magnitude. Analyses of strain rates in the Tibetan and Anatolian plateaus (Allmendin345 ger et al., 2007) demonstrated that infinitesimal maximum shear strain planes are paral346 lel to known, active, long-lived strike-slip faults (Fig. 5), and that principal axes are or347 thogonal to active, long-lived thrust and normal faults. Additionally, interseismic ver348 tical axis rotation is consistent with long term rotation observed in eastern Tibet, which 349 is essentially a rigid body rotation $\left(1.8 \pm 0.5^{\circ} / \mathrm{m} . \mathrm{y}\right.$.) bounded by the Ganze-Xianshuihe350 Xiaojiang fault system, and across the Bolivian orocline in the Central Andes, a rotation 351 due to distributed simple shear. In the latter area, the magnitude of the instantaneous 352 vertical axis rotation, integrated over 25 million years is the same as the long-term ver353 tical axis rotation observed by paleomagnetic studies (Allmendinger et al., 2005). Like354 wise, in most but not all areas, 2D interseismic dilatation rate from GNSS data common355 ly reflects the long term nature of the tectonic province: for example, the Aegean is an 356 area of crustal thinning, the Altiplano is one of crustal thickening, etc. (Allmendinger et 357 al., 2007).

The Basin and Range of the western United States is a particularly good area to 359 explore some of these questions (Fig. 4). At a regional scale, the areas of positive 2D di360 latation rate (crustal thinning) calculated from the PBO data set (UNAVCO, 2008) coin- 
361 cide with the loci of earthquake seismicity and the general distribution of Holocene 362 faults as mapped by the U.S. Geological Survey (2006), both of which are concentrated 363 in the topographic lows on either side of the province. The topographically higher, cen364 tral part of the province is less active tectonically and has nearly neutral, or even 365 slightly negative, 2D dilatation rate. This region correlates spatially with the newly de366 fined mantle “drip" (West et al., 2009).

The fit between geodetic and permanent deformation in the Basin and Range is 368 less good when examined at the scale of individual faults. Friedrich et al. (2003) argue 369 for "Wallace-type" behavior for the Wasatch fault, which may have experienced a Ho370 locene cluster of activity atypical of longer term behavior. A more glaring apparent dis371 cord between geodetic and permanent deformation can be found in north-central Ne372 vada. Across the Crescent normal fault, an east-west instantaneous shortening rate be373 tween two stations has been explained as a transient effect due to fault unloading (Frie374 drich et al., 2004; Wernicke et al., 2000), although more recent work indicates that the 375 geodetic signal is debatably anthropogenic and due to mining and groundwater with376 drawal (Gourmelen et al., 2007; Wernicke et al., 2008). Alternatively, when an alyzed in 377 two dimensions, the entire central Nevada region is one with slightly negative $2 \mathrm{D}$ dila378 tation rate indicating some more regional effect than a simple transient or local anthro379 pogenic effect (e.g., West et al., 2009). In any case, these examples and others (Niemi et 380 al., 2004; Oskin and Iriondo, 2004; Oskin et al., 2007) illustrate the potential dangers of 381 assuming a priori that short and long term strain accumulation on individual faults are 382 similar.

In some areas, interseismic deformation measured geodetically is conspicuously 384 at odds with regional long-term deformation as, for example, in the Chilean forearc. In385 terseismic loading while the Nazca-South American plate boundary is locked produces 386 large, margin-perpendicular shortening rate on the scale of the orogen. How ever, most 
387 of the structures in the Chilean Coastal Cordillera manifest margin-normal extension 388 (Allmendinger and González, 2009; González et al., 2003; Loveless et al., 2005; Niemeyer 389 et al., 1996; von Huene and Ranero, 2003), which would appear to be more compatible

390 with coseismic strain (Fig. 6). Though it is known that some permanent structures in the 391 Coastal Cordillera form coseismically (Loveless et al., 2009b), simple elastic dislocation 392 models suggest that interseismic strain accumulation on the subduction interface can 393 also produce a narrow belt of extension (Loveless et al., 2009a). The network of GPS sta394 tions in northern Chile is, unfortunately, too sparse to test this hypothesis and evalu a395 tion of interseismic deformation from InSAR is complicated by the atmospheric effect 396 resulting from persistent coastal fog (Loveless and Pritchard, 2008). Farther south in 397 Chile, post seismic transient deformation still dominates nearly 50 years after the great 398 Valdivia earthquake of 1960 (Khazaradze et al., 2002; Wang et al., 2007).

\section{5.2. Complementary nature of block modeling and strain analysis}

Despite very different assumptions, inversion of velocity fields for strain and ro401 tation rate, and the velocities predicted by elastic block modeling, are complementary. 402 Calculating the gradient of a geodetically constrained velocity field using a reasonably 403 large distance weighting parameter yields a picture of the nominally interseismic, large404 scale deformation at a plate boundary zone, while elastic block model analysis permits 405 estimation of activity on discrete structures that accommodate the relative block motion. 406 Figure 7 demonstrates this relationship in Japan, where densely spaced geodetic obser407 vations show a northeast trending high strain rate zone coincident with the Niigata408 Kobe Tectonic Zone (NKTZ, e.g., Sagiya et al., 2000). The structures comprising the 409 NKTZ in a block model (Loveless and Meade, 2009) are estimated to experience up to 15 $410 \mathrm{~mm} / \mathrm{yr}$ of dextral and reverse slip, consistent with the large magnitude shear and con411 traction rates given by the velocity gradient analysis. 
413 the existence and behavior of geologic structures, while block models inherently de414 scribe the geodetic velocity field as arising from processes occurring on a fixed geome415 try of interacting faults. At present, block models simulate the accumulation of interse416 ismic strain on faults using geometric extensions of idealized earthquake cycle models 417 (Savage and Burford, 1973; Savage, 1983) while additional lithospheric behaviors, such 418 as visco-elastic relaxation (e.g., Savage and Prescott, 1978; Hetland et al., 2008; Hilley et 419 al., 2009) are only beginning to be implemented into the theory.

420 The velocity gradient calculation provides information about vertical axis rota421 tion, horizontal distortion, and, assuming constant volume deformation, 2D dilatation, 422 which gives insight into the vertical tectonics of a region (England and Molnar, 2005; 423 Allmendinger et al., 2007). The nature of the calculation yields maps of these param e424 ters that vary smoothly throughout a region, with concentrations of strain occurring 425 around prominent crustal structures. Block models, on the other hand, predict velocity 426 fields that can vary smoothly or be characterized by discontinuities, depending on the 427 balance of block rotation versus elastic strain accumulation effects. An abrupt change in 428 the velocity field across a structure indicates a low degree of interseismic locking be429 tween the bounding crustal blocks, whereas a smoother velocity field gradient is the 430 signature of a fault actively accumulating elastic strain throughout the seismogenic 431 zone.

432 Allmendinger et al. (2007, their Figure 11) show that, given GPS stations span433 ning a fault and spaced similarly to typical modern networks, the strain field associated 434 with interseismic locking on the fault is nearly indistinguishable from that resulting 435 from a static offset, demonstrating consistency between interseismic and long-term 436 styles — and potentially magnitudes — of deformation. That is, a calculation of strain 437 from GNSS data is similar to the predicted long-term strain field, at least across a single 
structure so long as the fault slip rate has not changed in time. Block models, on the

439 other hand, are capable of distinguishing elastic deformation effects from the offset sig-

440 nal, thereby providing information about the locking depth of the fault or, more specifi-

441 cally, the spatial distribution of elastic strain accumulation on it. By differentiating the

442 velocity field in the gradient calculation, using weighting parameters appropriate for

443 evaluating regional tectonics, we potentially lose information about elastic strain accu-

444 mulation on individual structures, although constraining the strain accumulation re-

445 quires making the block model assumptions regarding fault geometry, processes, and 446 rheology.

447 Finally, calculation of velocity gradients might be considered to correspond to 448 the continuum class of models, but this is not necessarily the case. Where the continen449 tal blocks are large relative to the spacing of the GNSS network (and the weighting fac450 tor used in the case of the distance weighted algorithm), stable, internally little de451 formed blocks emerge naturally from the analysis. For example, the Tarim Basin clearly 452 emerges as a low strain rate block relative to Tibet and the Tien Shan, as does the Si453 chuan Basin on the eastern edge of Tibet (Allmendinger et al., 2007). Unfortunately, 454 within deforming regions, the spacing of current GPS networks remains too coarse to 455 allow the rigid blocks to emerge naturally as the output of a velocity gradient analysis. 456 Individual station spacing would need to be significantly less than the spacing of the 457 geodetically active fault network

458 5.3. Coseismic deformation most related to fault zone processes

459 Earthquakes can cause large ground displacements (up to $10 \mathrm{~s}$ of $\mathrm{m}$ in a few 460 seconds for Mw 8-9 earthquakes) and so it is not surprising that many earthquakes have 461 been observed geodetically (e.g., Yeats et al., 1997). The coseismic ground displacements 462 involve a static (permanent) offset of the ground surface that has been well imaged by 463 InSAR and GPS (e.g., Bürgmann et al., 2000b; Segall and Davis, 1997; Klotz et al., 1999). 
464 Additionally, a dynamic component (during the rupture propagation) can now be ob465 served with high-rate GNSS observations (e.g., Larson et al., 2003), providing comple466 mentary and in some cases, superior information to seismometers, which can record 467 near-field co-seismic displacements on scale. Geodetic measurements have recorded 468 significant post-seismic deformation (in some cases, exceeding the coseismic ground 469 motion, e.g., Heki et al., 1997) starting immediately after the earthquake and lasting 470 from several years to decades in the case of extremely large earthquakes.

The pattern of ground deformation from nearly all earthquakes has been success472 fully replicated by elastic dislocation sources representing finite slip on a fault plane. 473 These models even seem to work for earthquakes from depths of over $100 \mathrm{~km}$ (Peyrat et 474 al., 2006) because the materials still behave elastically during the short duration 475 (seconds) of the seismic rupture. In one case, it was argued that the asymmetric defor476 mation from a 1997 nearly-vertical strike-slip earthquake in Tibet required non-linear 477 elasticity (Peltzer et al., 1999), however the asymmetry can also be fit with a linear elas478 tic model that has a reversal of fault dip (e.g., Funning et al., 2007). At least a few earth479 quakes, however, show ground deformation related to triggered or induced motion on 480 secondary structures that are weak and compliant (Fialko et al., 2002; Fielding et al., 481 2004; Hearn and Fialko, 2009). A major topic of research is to use precise geodetic ob482 servations to understand the complex spatio-temporal slip during the earthquake event, 483 and how this slip is related to secondary motions, other earthquakes (and aftershocks), 484 and the location and nature of post-seismic deformation.

485 The geodetic observations are complementary to seismic studies of earthquakes 486 by combining both, we get a more complete picture of the earthquake location, mech an487 ism, and complexity. For example, Figure 8a shows that by using InSAR data, it was 488 possible to determine that the global earthquake catalogs mislocate a small earthquake 489 (Mw 5.3) in southern Iran by up to $70 \mathrm{~km}$, probably because of inaccuracies in the esti- 
mates in the seismic velocity structure. The precise earthquake location from the In-

491 SAR, allows the earthquake to be placed in geologic context (Figure 8b), and helps to

492 assess the subsurface dip of the fault. In a larger sense, earthquake parameters based on

493 geodetic (and seismic) parameters facilitates comparison with geologic structures and

494 allows assessment of any causal relations (e.g., Lohman et al., 2002; Loveless et al., 495 2009c).

496 5.4. Are differences between geodetic and geologic deformation rates real or an artifact of one or both types of measurements?

Several studies have shown that current geodetic (decadal) rates and patterns of deformation are different from deformation over the long-term (thousands to millions of years) measured by geologic mapping, paleoseismology, and seismic imaging (Friedrich et al., 2003; Friedrich et al., 2004; Hsu et al., 2003; Jackson, 1999; Oskin and Iriondo, 2004; Oskin et al., 2007; Peltzer et al., 2001; Wright et al., 2004). In particular, these

503 studies show that, in some areas, current deformation cannot explain recent geologic 504 features like mountain ranges and rift zones, or even the direction of faulting. These 505 studies also find that spatial variations in the rates of deformation are important — for example, only a subset of faults within a region might be active at any given time if 507 fault motion alternates or migrates within a fault system (e.g., Jackson, 1999; Niemi et 508 al., 2004). Furthermore, temporal variations in fault slip are also important. Fault activi509 ty can be clustered (e.g., Wallace, 1977) such that the observed geodetic rate may not be 510 representative of a long-term average depending on whether measurements are made 511 during a "cluster" or during a quiescent time (e.g., Oskin et al., 2008). In fact, earth512 quake clustering may be common, and is expected on theoretical grounds - even in 513 simple systems with a single earthquake on a single strike slip fault can affect the fre514 quency of earthquakes on nearby faults via visco-elastic processes (Kenner and Simons, 515 2005; Meade and Hager, 2005). 
While the differences between geologic and geodetic deformation rates might re-

517 flect real variations in deformation over space and time, several research groups are al518 so re-investigating whether apparent discrepancies might be resolved by considering 519 earthquake cycle models with temporarily complex behavior. For example, fault slip 520 models often assume that fault slip is occurring in an elastic homogeneous half-space, 521 but the inferred fault slip rate can change if the there are variations in elastic plate 522 thickness (e.g., Chéry, 2008) or visco-elastic rheology (Johnson et al., 2007; Segall, 2002).

523 In addition, the discrepancy between geodetic and geologic results is motivating new 524 field investigations that find more complex fault interactions than originally suspected 525 (Oskin et al., 2007).

\section{6. Future directions}

\subsection{Technological advances enabling future directions}

Several trends in space-based geodesy promise a resolution of some of the ambi529 guities that plague current interpretations. Continued monitoring and increased densi530 fication of existing GNSS networks will provide more uniformly spaced observations 531 which will help us to better evaluate whether a strain rate anomaly is real or simply re532 flects station clustering in areas of high strain. The on-going switch from campaign to 533 continuous GNSS data will provide higher accuracy velocities with better resolved ver534 tical components that will allow for three-dimensional strain analysis. However, higher 535 errors in the calculation of vertical strain components will remain because the stations 536 only occur on the surface of the earth and are thus very nearly coplanar except in areas

537 of very high relief. The switch to continuous data will have another, more profound re538 sult: it will provide time series of deformation that will allow the capture of transients, 539 as described below.

At least four technical innovations will increase the use of InSAR for tectonic

541 studies. A primary limitation of the wide-spread use of InSAR in the last decades has 
542 been the lack of sufficient observations, but this is likely to change within the next dec543 ade. Currently, seven different SAR satellites (or constellations of satellites) are in Earth 544 orbit: European Space Agency's ERS-2 and Envisat; Japanese Space Agency's ALOS;

545 Canadian Space Agency's Radarsat-1 and -2; German Space Agency's TERRASAR-X; 546 and the Italian Space Agency's COSMOSky-MED. Several more missions are planned in 547 the next few years, with an exciting prospect being NASA's DESDynI satellite which 548 would be the first dedicated to InSAR, and with a likely launch date in 2017 . The in549 creased number of satellites will increase the spatial and temporal frequency of observa550 tions. While individual SAR scenes from the different satellites cannot (generally) be 551 combined to form interferograms, temporally overlapping interferograms from differ552 ent satellites (or orbital tracks of a single satellite) can be combined to allow multiple 553 components of the three-dimensional deformation (or velocity) field to be recovered 554 (e.g., Fialko et al., 2005) and provide constraints on the temporal evolution of deforma555 tion (e.g., Pritchard and Simons, 2006). With multiple components of the deformation 556 field, it would be possible to do a strain analysis and do other types of modeling in 557 combination with available GPS data. Another limitation for past InSAR studies has 558 been that the observations were restricted to arid and urban regions because vegetation 559 changes masked tectonic changes. The use of longer radar wavelengths (L-band or 23 $560 \mathrm{~cm}$ like on the ALOS and DESDynI satellites) allows InSAR measurements in vegetated 561 areas. The development of new computer algorithms like persistent-scatterer InSAR 562 (Ferretti et al., 2001; Hooper et al., 2004) has also permitted InSAR measurements to be 563 made in vegetated areas and the further development and application of these tech564 niques along with increased frequency of SAR observations will further expand regions 565 where InSAR measurements of tectonic deformation can be made. A particularly frustrating aspect of current analyses of GNSS data is the difficulty 567 of combining data sets collected by different groups of investigators. This difficulty 
arises from the fact that different research groups use different reference frames. While

569 different universal reference frames exist, many older campaign networks persist in

570 publishing processed data in their own unique reference frames. Thus overlapping data

571 from different surveys cannot be combined and analyzed together. In South America,

572 for example, the data from the CAP network (Brooks et al., 2003; Kendrick et al., 2001)

573 cannot be combined with the almost completely overlapping GFZ network (Khazaradze

574 and Klotz, 2003; Klotz et al., 2001) and IPGP (Chlieh et al., 2004) networks. While there

575 are mathematical approaches to combining data from different networks (Dong et al.,

576 1998), increased collaboration between groups and open access to the raw observations

577 (for example in the UNAVCO data archive) would ensure that disparate networks can

578 be combined into a common reference frame.

579 6.2. Transients and their relations to processes

For a structural geologist, short-term geodetic measurement can reveal processes

581 that might be valuable when interpreting the geologic record. Many different types of

582 "transient" deformation signals involve the cycling of fluids or other dynam ic processes

583 that might not be apparent when studying fossilized systems. In addition to the inter -

584 and coseismic periods, spatially and temporally dense geodetic data have revealed a

585 broad spectrum of transient or intermediary behavior that occurs during the seismic

586 cycle, including post-seismic and/ or pre-seismic deformation caused by ductile, poro-

587 elastic, frictional process, and fault zone healing (e.g., Bürgmann and Dresen, 2008; H e-

588 ki et al., 1997; Peltzer et al., 1996; Fielding et al., 2009), slow earthquakes or silent slip

589 events (e.g., Schwartz and Rokosky, 2007), and partial interseismic coupling on seismo-

590 genic faults. Additionally, transitory deformation from glacier mass balance changes

591 (e.g., Hooper and Pedersen, 2007; Pinel et al., 2007) and fluid related processes such as

592 magmatic injection (e.g., Smith et al., 2004; Chang et al., 2007) have been documented.

593 Comparing these behaviors to long-term deformation begs the question of whether 
594 transient phenomena leave a distinct permanent mark or are lost among signals of cose595 ismic effects in the geologic record.

596 Most tectonic transient phenomena induce surface displacements in a direction 597 similar to that of coseismic deformation. For example, the well documented periodic 598 slow slip events on the Cascadia subduction zone interface produce a reversal of the in599 terseismic trend recorded at forearc GNSS stations (Dragert et al., 2001; Dragert et al., 600 2004). While earthquakes produce sudden offsets that are documented in stratigraphy, 601 aseismic processes may act over such long time scales and be characterized by such 602 small magnitude deformation that they do not produce a distinct geologic signal in the 603 fault zone itself. Along the Parkfield segment of the San Andreas Fault, Toké et al. (Toké 604 et al., 2006 and references therein) note that while aseismic fault creep and earthquakes 605 can produce similar styles of stratigraphic deformation, only earthquakes can result in 606 fissuring, liquefaction, and colluvial wedges, thus introducing some distinction between 607 the two types of slip behavior in the paleoseismic record. Practically, Toké et al. (2006) 608 found only evidence of moderate $(\mathrm{M} \sim 6)$ earthquakes, considering aseismic creep as an 609 unquantified factor in constructing sag ponds and other geomorphic evidence of fault 610 slip.

Post-seismic deformation has been clearly separated from coseismic offsets in the 612 geodetic record by its time dependent nature. Whereas the signal of an earthquake in a 613 geodetic time series appears as a step function, post-seismic displacements often follow 614 a non-linear pattern for some time period after the earthquake. Because the time scale 615 of the decay of post-seismic deformation is typically on the order of years to decades, 616 even for the greatest of earthquakes, it is difficult to separate it from the coseismic signal 617 in the geologic record. Instead, the combined effects of co- and post-seismic deforma618 tion may be interpreted as resulting from an earthquake with an overestimated magn i619 tude. For example, post-seismic GPS displacements following the $1994 \mathrm{Mw}=7.4$ Sanri- 
$620 \mathrm{ku-oki}$ earthquake offshore northern Japan have been interpreted as the result of after-

621 slip on the subduction interface, the equivalent magnitude of which exceeds that of the

622 earthquake (Heki et al., 1997). An idealized geologic record, recording 100\% of the

623 earthquake and after-slip, would be interpreted as a single event exceeding the assigned

624 earthquake magnitude.

625 Transient processes have been discovered by using dense time series at a given 626 location but have also been discovered when looking at InSAR snapshots of the spatial 627 extent of deformation across a region. For example, Fialko et al., (2002) discovered mo628 tion on a series of faults 10s of kilometers away from the main fault ruptures (indicating 629 the characteristics of fault damage zones).

\section{Conclusions}

Space-based geodetic data have considerable potential to revolutionize our un632 derstanding of active structures. Many of the questions surrounding the interpretation 633 of these data - is most of the deformation concentrated on networks of large faults se634 parated by relatively stiff elastic blocks? How does spatial sample distribution affect our 635 perception of deformation? etc. - have direct parallels for structural geologists in the 636 context of finite strain: how many thrust faults have to be included to capture the strain 637 in a thrust belt? How do you measure strain in the middle of a heterogeneous simple 638 shear zone? In one sense, however, there is a profound difference: geodetic data truly 639 capture a geologically instantaneous snapshot in time. Because geodetic data span 640 much less time than an individual earthquake cycle, we must use data from different 641 locations as a proxy for time. That is, we are trying to understand the complete fault be642 havior by piecing together interseismic deformation from one fault with coseismic and 643 post-seismic behaviors from other faults in other areas. In geological study of deformed 644 rocks, we can occasionally eke out the progression of events in a single area. That ge o645 logic record, however, may never fully record the transient events that are emerging 
646 from geodetic data. Likew ise, the geodetic record is still too young to capture faults that

647 may have had an important role in Cenozoic mountain building, but have ceased their 648 activity, or are temporarily quiescent.

\section{Acknow ledgments}

650 We gratefully acknowledge the intellectual influence that numerous colleagues 651 and students have had on our understanding of the topics reviewed in this paper. We 652 appreciate Rowena Lohman's help with Figure 8. Allmendinger would particularly like 653 to recognize Néstor Cardozo, Mike Bevis, Ben Brooks, Bob Smalley, Gabriel González, 654 and Phoebe Judge, though they may not agree with all of the conclusions in this paper. 655 Reviews by Roland Bürgmann, an anonymous reviewer, and Editor Bill Dunne signifi656 cantly improved the manuscript. His work on these topics has, over the years, been 657 supported by grants from the National Science Foundation, including grants EAR 658 0087431, EAR-0337496, EAR-0510785, and EAR-0738507; Pritchard also gratefully ac659 knowledges support as a co-principal investigator on the latter two grants. Meade and 660 Loveless were supported by Harvard University. 


\section{References cited}

Allmendinger, R. W., Smalley R., Bevis M., Caprio H., Brooks B., 2005. Bending the Bolivian orocline in real time. Geology 33, 905-908. doi:10.1130/ G21779.1.

Allmendinger, R. W., Reilinger R., Loveless J. P., 2007. Strain and Rotation Rate from GPS in Tibet, Anatolia, and the Altiplano. Tectonics 26, TC3013. doi:10.1029/2006TC002030.

Allmendinger, R. W., González G. G., 2009. Neogene to Quaternary Tectonics of the Coastal Cordillera, northern Chile. Tectonophysics in press.

Argus, D. F., Heflin M. B., Peltzer G., Crampé F., Webb F. H., 2005. Interseismic strain accumulation and anthropogenic motion in metropolitan Los Angeles. J. Geophys. Res 110, 1-26 (B04401). doi:10.1029/ 2003JB002934.

Avouac, J. P., Tapponnier P., 1993. Kinematic Model of Active Deformation in CentralAsia. Geophysical Research Letters 20, 895-898.

Banerjee, P., Bürgmann R., 2002. Convergence across the Northwest Himalaya from GPS measurements. Geophysical Research Letters 29,1652 , 10.1029/2002GL015184.

Bawden, G. W., Thatcher W., Stein R. S., Hudnut K. W., Peltzer G., 2001. Tectonic contraction across Los Angeles after removal of groundwater pumping effects. $\mathrm{Na}$ ture $412,812-815$.

Bennett, R. A., Wernicke B. P., Niemi N. A., Friedrich A. M., Davis J. L., 2003. Contemporary strain rates in the northern Basin and Range Province from GPS data $\mathrm{Pa}$ gination: 31 . Tectonics 22, 1008, doi:10.1029/2001TC001355.

Berardino, P., Fornaro G., Lanari R., Sansosti E., 2002. A new algorithm for surface d eformation monitoring based on small baseline differential SAR interferograms. IEEE Transactions on Geoscience and Remote Sensing 40, 2375-2383.

Bilham, R., Gaur V. K., Molnar P., 2001. Himalayan seismic hazard. Science 293, $1442-$ 1444.

Bilham, R., 2006. Dangerous tectonics, fragile buildings, and tough decisions. Science $311,1873-1875$.

Blew itt, G., Lavallée D., Clarke P., Nurutd inov K., 2001. A new global mode of Earth d eformation: Seasonal cycle detected. Science 294, 2342-2345.

Brooks, B. A., Bevis M., R. Smalley J., Kendrick E., Manceda R., Lauria E., Araujo M., 2003. Crustal Motion in the Southern Andes (26-36 $\left.{ }^{\circ}\right)$ : do the Andes behave like a microplate?. Geochemistry, Geophysics, Geosystems - $\mathrm{G}^{\wedge} 3$ 4, 1085, doi:10.1029/2003GC000505.

Bürgmann, R., Rosen P. A., Fielding E. J., 2000a. Synthetic aperture radar interferometry to measure Earth's surface topography and its deformation. Ann. Rev. Earth Planet. Sci 28, 169-209. 
Bürgmann, R., Rosen P. A., Fielding E. J., 2000b. Synthetic aperture radar interferometry to measure Earth's surface topography and its deformation. Annual Review of Earth and Planetary Sciences 28, 169-209.

Bürgmann, R., Dresen G., 2008. Rheology of the lower crust and upper mantle: Evidence from rock mechanics, geodesy, and field observations. Annual Reviews Earth Planetary Science 36, 531-567.

Cardozo, N., Allmendinger R. W., 2009. SSPX: A program to compute strain from displacement/velocity data. Computers \& Geosciences 35, 1343-1357, doi:d oi:10.1016/ j.cageo.2008.05.008.

Chang, W. L., Smith R. B., Wicks C., Farrell J. M., Puskas C. M., 2007. Accelerated uplift and magmatic intrusion of the Yellowstone Caldera, 2004 to 2006. Science 318, 952. doi:10.1126/ science.1146842.

Chéry, J., 2008. Geodetic strain across the San Andreas fault reflects elastic plate thickness variations (rather than fault slip rate). Earth and Planetary Science Letters 269, 351-364.

Chlieh, M., de Chabalier J. B., Ruegg J. C., Armijo R., Dmowska R., Campos J., Feigl K. L., 2004. Crustal deformation and fault slip during the seismic cycle in the North Chile subduction zone, from GPS and InSAR observations. Geophysical Journal International 158, 695-711. doi:10.1111/ j.1365-246X.2004.02326.x.

Delouis, B., Philip H., Dorbath L., Cisternas A., 1998. Recent crustal deformation in the Antofagasta region (northern Chile) and the subduction process. Geophysical Journal International 132, 302-338. doi:10.1046/ j.1365-246x.1998.00439.x.

Dong, D., Herring T. A., King R. W., 1998. Estimating regional deformation from a combination of space and terrestrial geod etic data. Journal of Geodesy 72, 200-214.

Dragert, H., Wang K., James T. S., 2001. A silent slip event on the deeper Cascadia su bduction interface. Science 292, 1525-1528.

Dragert, H., Wang K., Rogers G., 2004. Geodetic and seismic signatures of episodic tremor and slip in the northern Cascadia subduction zone. Earth, Planets, and Space 56, 1143--1150.

England, P., McKenzie D., 1982. A thin viscous sheet model for continental deformation. Geophysical Journal of the Royal Astronomical Society 70, 295-321.

England, P., Molnar P., 2005. Late Quaternary to decadal velocity fields in Asia. Journal of Geophysical Research 110, B12401. doi:10.1029/ 2004JB003541.

Ferretti, A., Prati C., Rocca F., 2001. Permanent scatterers in SAR interferometry. IEEE Transactions on Geosciene and Remote Sensing 39, 8-20.

Fialko, Y., Sandwell D., Agnew D., Simons M., Shearer P., Minster B., 2002. Deformation on Nearby Faults Induced by the 1999 Hector Mine Earthquake. Science 297, 1858-1862. 
Fialko, Y., Sandwell, D., Simons, M., Rosen, P., 2005. Three-dimensional deformation caused by the Bam, Iran, earthquake and the origin of the shallow slip deficit, Nature, 435, 295-299.

Fialko, Y., 2006. Interseismic strain accumulation and the earthquake potential on the southern San Andreas fault system. Nature 441, 968-971. doi:10.1038/ nature04797.

Fielding, E. J., Wright T. J., Muller J., Parsons B. E., Walker R., 2004. Aseismic deform ation of a fold-and-thrust belt imaged by synthetic aperture radar interferometry near Shahdad, southeast Iran. Geology 32, 577-580.

Fielding, E. J., Talebian M., Rosen P. A., Nazari H., Jackson J. A., Ghorashi M., Walker R., 2005. Surface ruptures and building damage of the 2003 Bam, Iran, earthquake mapped by satellite synthetic aperture radar interferometric correlation. Journal of Geophysical Research 110, .

Fielding, E. J., Lundgren P. R., Buergmann R., Funning G. J., 2009. Shallow fault-zone dilatancy recovery after the 2003 Bam earthquake in Iran. Nature 458, 64-68. doi:10.1038/ nature07817.

Friedrich, A. M., Wernicke B. P., Niemi N., Bennett R. A., Davis J. L., 2003. Comparison of geodetic and geologic data from the Wasatch region, Utah, and implications for the spectral character of Earth deformation at periods of 10 to 10 million years. J. Geophy. Res 108, 10.1029/ 2001JB000682. doi:10.1029/ 2001 JB000682.

Friedrich, A. M., Lee J., Wernicke B. P., Sieh K., 2004. Geologic context of geodetic data across a Basin and Range normal fault, Crescent Valley, Nevada. Tectonics 23, 10.1029/ 2003TC001528. doi:10.1029/2003TC001528.

Funning, G. J., Parsons B., Wright T. J., 2007. Fault slip in the 1997 Manyi, Tibet earthquake from linear elastic modelling of InSAR displacements. Geophysical Journal International 169, 988-1008. doi:10.1111/ j.1365-246X.2006.03318.x.

González, G., Cembrano J., Carrizo D., Macci A., Schneider H., 2003. The link between forearc tectonics and Pliocene-Quaternary deformation of the Coastal Cordillera, northern Chile. Journal of South American Earth Sciences 16, 321-342.

Gourmelen, N., Amelung F., Casu F., Manzo M., Lanari R., 2007. Mining-related ground deformation in Crescent Valley, Nevada: Implications for sparse GPS networks. Geophysical Research Letters 34, 9309. doi:10.1029/ 2007GL029427.

Haines, A. J., Holt W. E., 1993. A procedure for obtaining the complete horizontal motions within zones of distributed deformation from the inversion of strain rate data. Journal of Geophysical Research, B, Solid Earth and Planets 98, 12,05712,082 .

Hearn, E. H., Fialko Y., 2009. Can compliant fault zones be used to measure absolute stresses in the upper crust?. Journal Of Geophysical Research-Solid Earth 114, B04403. doi:10.1029/2008JB005901. 
Heki, K., Miyazaki S., Tsuji H., 1997. Silent fault slip following an interplate thrust earthquake at the Japan Trench. Nature 386, 595-598.

Heki, K., 2001. Seasonal modulation of interseismic strain buildup in northeastern Japan driven by snow loads. Science 293, 89-92.

Hetland, E. A., Simons M., Dunham E. M., Kanda R. V., 2008. Interseismic Deformation and the Mechanical Behavior of Megathrusts: Transient Postseismic Creep, Stress Shadows, and Megathrust Rheology. EOS Transactions, AGU 89, .

Hilley, G. E., Johnson K. M., Wang M., Shen Z. K., Burgmann R., 2009. Earthquake-cycle deformation and fault slip rates in northern Tibet. Geology 37, 31-34. doi:10.1130/ G25157A.1.

Hofmann-Wellenhof, B., Lichtenegger, H., Wasle, E., 2008. GNSS--global navigation satellite systems: GPS, GLONASS, Galileo, and more, Springer, 516 pp.

Holt, W. E., Shen-Tu, B., Haines, J., Jackson, J., 2000. On the determination of selfconsistent strain rate fields within zones of distribution continental deformation. In: Richards M.A. et al. (Eds.), The history and dynamics of global plate motions. Geophysical Monograph American Geophysical Union, Washington, D.C., pp. 113141.

Hooper, A., Zebker H., Segall P., Kampes B., 2004. A new method for measuring deformation on volcanoes and other natural terrains u sing InSAR persistent scatterers. Geophys. Res. Lett 31, 611-615. doi:10.1029/2004GL021737.

Hooper, A., Pedersen, R., 2007. Deformation due to magma movement and ice unloading at Katla volcano, Iceland, detected by persistent scatterer InSAR. In: Proceedings EN VISAT Symposium, EN VISAT, Montreux, .

Hsu, Y., Simons M., Yu S., Kuo L., Chen H., 2003. A two-dimensional dislocation model for interseismic deformation of the Taiwan mountain belt. Earth Planet. Sci. Lett 211, 287-294.

Jackson, J., 1999. Fault death: A perspective from actively deforming regions. J. Struct. Geol 21, 1003-1010.

Johnson, K. M., Hilley G. E., Burgmann R., 2007. Influence of lithosphere viscosity stru cture on estimates of fault slip rate in the Mojave region of the San Andreas fault system. Journal of Geophysical Research 112, B07408. doi:10.1029/ 2006JB004842.

Kendrick, E., Bevis M., Smalley R., Brooks B., 2001. An integrated crustal velocity field for the Central Andes. Geochemistry, Geophysics, Geosystems - G 32 , 10.1029/2001GC000191.

Kenner, S. J., Simons M., 2005. Temporal clustering of major earthquakes along individual faults due to post-seismic reloading. Geophysical Journal International 160, 179-194. 
Khazaradze, G., Klotz J., 2003. Short- and long-term effects of GPS measured crustal deformation rates along the south central Andes. Journal of Geophysical Research 108, 2289. doi:10.1029/2002JB001879.

Khazaradze, G., Wang K., Klotz J., Hu Y., He J., 2002. Prolonged post-seismic deformation of the 1960 great Chile earthquake and implications for mantle rheology. Geophysical Research Letters 29, doi:10.1029/2002GL015986.

King, G. C. P., 1983. The accommodation of large strains in the upper lithosphere of the Earth and other solids by self-similar fault systems: the geometrical origin of bvalue. Pure and Applied Geophysics 121, 761-815.

Klotz, J., Angermann D., Michel G., Porth R., Reigber C., Reinking J., Viramonte J., Perdomo R., Rios V., Barrientos S., Barriga R., Cifuentes O., 1999. GPS-derived deformation of the Central Andes including the 1995 Antofagasta $\mathrm{Mw}=8.0$ Earthquake. Pure and Applied Geophysics 154, 709-730.

Klotz, J., Khazaradze G., Angermann D., Reigber C., Perdomo R., Cifuentes O., 2001. Earthquake cycle dominates contemporary crustal deformation in Central and Southern Andes. Earth and Planetary Science Letters 193, 437-446.

Kreemer, C., Holt W. E., Haines A. J., 2003. An integrated global model of present-day plate motions and plate boundary deformation. Geophysical Journal International 154, 8-34.

Kumar, S., Wesnousky S. G., Rockw ell T. K., Briggs R. W., Thakur V. C., Jayangondaperumal R., 2006. Paleoseismic evidence of great surface rupture earthquakes along the Indian Himalaya. Journal of Geophysical Research 111, .

Larson, K. M., Bodin P., Gomberg J., 2003. Using 1-Hz GPS data to measure deformations caused by the Denali Fault earthquake. Science 300, 1421-1424.

Lohman, R. B., Simons M., Savage B., 2002. Location and mechanism of the Little Skull Mountain earthquake as constrained by satellite radar interferometry and seismic waveform modeling. Journal of Geophysical Research-Solid Earth 107, doi:10.1029/ 2001JB000627.

Lohman, R. B., Simons M., 2005. Locations of selected small earthquakes in the Zagros mountains. Geochemisty Geophysics Geosystems 6, Q03001. doi:10.1029/2004GC000849.

Loveless, J. P., Hoke G. D., Allmendinger R. W., González G., Isacks B. L., Carrizo D. A., 2005. Pervasive cracking of the northern Chilean Coastal Cordillera: New evidence of forearc extension. Geology 33, 973-976. doi:10.1130/ G22004.1.

Loveless, J. P., Pritchard M. E., 2008, Motion of upper-plate faults during subduction zone earthquakes: Case of the Atacama Fault System, northern Chile, Geochem., Geophys., Geosyst., 9, Q12017, doi: 10.1029/ 2008GC002155.

Loveless, J. P., Meade B. J., 2009. Geodetic imaging of plate motions, slip rates, and partitioning of deformation in Japan. Journal of Geophysical Research in review, . 
Loveless, J. P., Allmendinger R. W., Pritchard E., González G., 2009a. Normal and reverse faulting driven by the subduction zone earthquake cycle in the northern Chilean forearc. Tectonics submitted.

Loveless, J. P., Allmendinger R. W., Pritchard M. E., Garroway J. L., González G. G., 2009b. Surface cracks record long-term seismic segmentation of the Andean margin. Geology 37, 23-26. doi:10.1130/ G25170A.1.

Loveless, J. P., Pritchard M. E., Kukowski N., 2009c. Testing mechanisms of subduction zone segmentation and seismogenesis with slip distributions from recent Andean earthquakes. Tectonophysics in press.

Malvern, L. E., 1969. Introduction to the mechanics of a continuous medium, PrenticeHall, Inc., Englew ood Cliffs, N.J., .

Marrett, R. A., Allmendinger R. W., 1990. Kinematic analysis of fault-slip data. Journal of Structural Geology 12, 973-986.

Marrett, R. A., Allmendinger R. W., 1991. Estimates of strain due to brittle faulting: Sampling of fault populations. Journal of Structural Geology 13, 735-738.

Marrett, R. A., Allmendinger R. W., 1992. The amount of extension on "small" faults: An example from the Viking Graben. Geology 20, 47-50.

Matsu'ura, M., Jackson D. D., Cheng A., 1986. Dislocation model for aseismic crustal d eformation at Hollister, California. Journal of Geophysical Research 91, 2661-2674.

McCaffrey, R., 2002. Crustal block rotations and plate coupling. In: Stein S., Freymueller J. (Eds.), Plate Boundary Zones. 30, American Geophysical Union, Washington, D.C., pp. 101-122.

McQuarrie, N., 2004. Crustal scale geometry of the Zagros fold --thrust belt, Iran. Journal of Structural Geology 26, 519-535.

Meade, B. J., Hager B. H., 2005. Block models of crustal motion in southern California constrained by GPS measurements. Journal of Geophysical Research 110, B03403. doi:10.1029/ 2004JB003209.

Meade, B. J., 2007. Power-law distribution of fault slip-rates in southern California. Geophysical Research Letters 34, L23307. doi:10.1029/ 2007 GL031454.

Meade, B. J., Loveless J. P., 2009. Block modeling with multiple fault network geometries and a linear elastic coupling estimator in spherical coordinates. Bulletin of the Seismological Society of America, in press.

Menke, W., 1984. Geophysical Data Analysis: Discrete Inverse Theory, Academic Press, Orlando, $260 \mathrm{pp}$.

Niemeyer, H., González G., Martínez-De Los Ríos E., 1996. Evolución tectónica cen ozoica del margen continental activo de Antofagasta, norte de Chile. Revista Geológica de Chile 23, 165-186. 
Niemi, N. A., Wernicke B. P., Friedrich A. M., Simons M., Bennett R. A., Davis J. L., 2004. BARGEN continuous GPS data across the eastern Basin and Range province, and implications for fault system dynamics. Geophysical Journal International 159, 842-862.

Oskin, M., Iriondo A., 2004. Large-magnitude transient strain accumulation on the Blackwater fault, Eastern California Shear Zone. Geology 32, 313-316.

Oskin, M., Perg L., Blumentritt D., Mukhopadhyay S., Iriondo A., 2007. Slip rate of the Calico fault: Implications for geologic versus geodetic rate discrepancy in the Eastern California Shear Zone. J. Geophys. Res 112, d doi:10.1029/ 2006JB004451.

Oskin, M., Perg L., Shelef E., Strane M., Gurney E., Singer B., Zhang X., 2008. Elevated shear zone loading rate during an earthquake cluster in eastern California. Geology 36, 507-510. doi:10.1130/ G24814A.1.

Peltzer, G., Rosen P., Rogez F., Hudnut K., 1996. Postseismic Rebound in Fault Step Overs Caused by Pore Fluid Flow. Science 273, 1202-1204. doi:10.1126/ science.273.5279.1202.

Peltzer, G., Crampé F., King G., 1999. Evidence of nonlinear elasticity of the crust from the Mw7. 6 Manyi (Tibet) earthquake. Science 286, 272. doi:10.1126/ science.286.5438.272.

Peltzer, G., Crampe F., Hensley S., Rosen P., 2001. Transient strain accumulation and fault interaction in the eastern California shear zone. Geology 29, 975-978.

Peyrat, S., Campos J., de Chabalier J. B., Perez A., Bonvalot S., Bou in M. P., Legrand D., Nercessian A., Charade O., Patau G., others O., 2006. Tarapacá intermediatedepth earthquake (Mw 7.7, 2005, northern Chile): A slab-pull event with horizontal fault plane constrained from seismologic and geodetic observations. Geophysical Research Letters 33, L22308. doi:10.1029/ 2006GL027710.

Pinel, V., Sigmundsson F., Sturkell E., Geirsson H., Einarsson P., Gudmundsson M. T., Hognadottir T., 2007. Discriminating volcano deformation due to magma movements and variable surface loads: application to Katla subglacial volcano, Iceland. Geophysical Journal International 169, 325-338.

Pritchard, M. E., Simons M., Rosen P. A., Hensley S., Webb F. H., 2002. Co-seismic slip from the 1995 July $30 \mathrm{Mw}=8.1$ Antofagasta, Chile, earthquake as constrained by InSAR and GPS observations. Geophysical Journal International 150, 362-376.

Pritchard, M. E., Simons, M., 2006, An aseismic fault slip pulse in northern Chile and along-strike variations in seismogenic behavior, J. Geophys. Res., 111, B08405, doi: 10.1029/2006JB004258.

Ramsay, J. G., Graham R. H., 1970. Strain variation in shear belts. Canadian Journal of Earth Sciences 7, 786-813.

Reilinger, R., Brown, L., 1981. Neotectonic deformation, near-surface movements and systematic errors in U.S. releveling measurements: implications for earthquake 
prediction. In: Simpson D.W., Richards P.G. (Eds.), Earthquake Prediction: An International Review, Maurice Ewing Sr., Vol. 4 AGU, Washington, D. C., pp. 422440.

Reilinger, R. E., Ergintav S., Bürgmann R., McClusky S., Lenk O., Barka A., Gurkan O., Hearn L., Feigl K. L., Cakmak R., Aktug B., Ozener H., Toksoz M. N., 2000. Coseismic and postseismic fault slip for the 17 August 1999, M = 7.5, Izmit, Turkey earthquake. Science 289, 1519-1524.

Rosen, P. A., Hensley S., Joughin I. R., Li F. K., Rodríguez S. N. M. A. E., Goldstein R. M., 2000. Synthetic Aperture Radar Interferometry. Proceedings of the IEEE 88, 333-382.

Sagiya, T., Miyazaki S., Tada T., 2000. Continuous GPS array and present-day crustal deformation of Japan. Pure and Applied Geophysics 157, 2303-2322.

Savage, J. C., Burford R. O., 1973. Geodetic determination of relative plate motion in central California. Journal of Geophysical Research 78, 832-845.

Savage, J. C., Prescott W. H., 1978. Asthenosphere readjustment and the earthquake cycle. Journal of Geophysical Research 83, 3369-3376.

Savage, J. C., 1983. A dislocation model of strain accumulation and release at a subduction zone. Journal of Geophysical Research 88, 4984-4996.

Schmidt, D. A., Bürgmann R., 2003. Time-dependent land uplift and subsidence in the Santa Clara valley, California, from a large interferometric synthetic aperture radar data set. J. Geophys. Res 108, 2416. doi:10.1029/2002JB002267.

Schwartz, S. Y., Rokosky J. M., 2007. Slow slip events and seismic tremor at circumPacific subduction zones. Reviews of Geophysics 45, RG3004. doi:10.1029/2006RG000208.

Segall, P., Davis J. L., 1997. GPS applications for geodynamics and earthquake studies. Annual Review of Earth and Planetary Sciences 25, 301-336.

Segall, P., 2002. Integrating geologic and geodetic estimates of slip rate on the San Andreas fault system. International Geology Review 44, 62-82.

Shen, Z., Jackson D. D., Ge B. X., 1996. Crustal deformation across and beyond the Los Angeles Basin from geodetic measurements. Journal of Geophysical Research $101,27,957-27,980$.

Shen, Z. K., Lu J., Wang M., Burgmann R., 2005. Contemporary crustal deformation around the southeast borderland of the Tibetan Plateau. Journal Geophysical Research 110, d oi:10.1029/2004JB003421.

Simons, M., Fialko Y., Rivera L., 2002. Coseismic deformation from the 1999 M w 7.1 Hector Mine, California, earthquake as inferred from InSAR and GPS observations. Bulletin of the Seismological Society of America 92, 1390-1402. 
Smith, K. D., von Seggern D., Blew itt G., Preston L., Anderson J. G., Wernicke B. P., Davis J. L., 2004. Evidence for deep magma Injection beneath Lake Tahoe, N evadaCalifornia. Science 305, 1277. doi:10.1126/ science.1101304.

Tatar, M., Hatzfeld D., Ghafory-Ashtiany M., 2004. Tectonics of the Central Zagros (Iran) deduced from microearthquake seismicity. Geophysical Journal International 156, 255-266. doi:10.1111/ j.1365-246X.2003.02145.x.

Thatcher, W., 1995. Microplate versus continuum descriptions of active tectonic deformation. Journal of Geophysical Research 100, 3885-3894.

Thatcher, W. R., 2003. GPS constraints on the kinematics of continental deformation. International Geology Review 45, 191-212.

Thatcher, W., 2007. Microplate model for the present-day deformation of Tibet. Journal of Geophysical Research 112, B01401. doi:10.1029/2005JB004244.

Thatcher, W., 2009. How the Continents Deform: The Evidence From Tectonic Geodesy . Annual Review of Earth and Planetary Sciences 37, 14.1-14.26.

Toké, N. A., Arrowsmith J. R., Young J. J., Crosby C. J., 2006. Paleoseismic and Postseismic Observations of Surface Slip along the Parkfield Segment of the San Andreas Fault. Bulletin of the Seismological Society of America 96, S221-S238.

UNAVCO, 2008. Plate boundary observatory. GPS Data Products http:/ / pboweb.unavco.org/ ?pageid=88, date accessed: 27 July 2009.

U.S. Geological Survey, Utah Geological Survey, Nevad a Bureau of Mines and Geology, California Geological Survey, 2006. Quaternary fault and fold database of the United States. http:/ / earthquakes.usgs.gov/ regional/ qfaults/, date accessed: 18 October 2006.

von Huene, R., Ranero C. R., 2003. Subduction erosion and basal friction along the sediment-starved convergent margin off Antofagasta, Chile. Journal of Geophysical Research 108, .

Wallace, R. E., 1977. Profiles and ages of young fault scarps, north-central Nevada. Geological Society of America Bulletin 88, 1267-1281.

Wang, K., Hu Y., Bevis M., Kendrick E., Smalley R., Lauria E., 2007. Crustal motion in the zone of the 1960 Chile earthquake: Detangling earthquake-cycle deformation and forearc-sliver translation. Geochemistry Geophysics Geosystems 8, . doi:10.1029/2007GC001721.

Wernicke, B. P., Friedrich A. M., Niemi N. A., Bennett R. A., Davis J. L., 2000. Dynamics of plate boundary fault systems from Basin and Range Geodetic Network (BARGEN) and geologic data. GSA Today 10, 1-7.

Wernicke, B., Davis J. L., Niemi N. A., Lu ffi P., Bisnath S., 2008. Active megadetachment beneath the western United States. Journal of Geophysical Research B 113, B11409. doi:10.1029/2007JB005375. 
West, J. D., Fouch M. J., Roth J. B., Elkins-Tanton L. T., 2009. Vertical mantle flow associated with a lithospheric drip beneath the Great Basin. Nature Geoscience 2, 439444. doi:10.1038/ NGEO526.

Wright, T. J., Parsons B., England P. C., Fielding E. J., 2004. InSAR observations of low slip rates on the major faults of western Tibet. Science 305, 236-239.

Yeats, R. S., Sieh, K., Allen, C. R., 1997. Geology of Earthquakes, Oxford University Press, Oxford, UK, 568 pp.

Zhang, P., Zhengkang S., Min W., Weijun G., Bürgmann R., Molnar P., Qi W., Zhijun N., Jianzhong S., Jianchun W., Hanrong S., You X., 2004. Continuous deformation of the Tibetan Plateau from Global Positioning System data. Geology 32, 809-812. 


\section{Figure captions}

Figure 1. Illustration of the case of three GNSS stations spanning a left-lateral fault. (a) undeformed configuration. The circle inscribed in the triangle defined by the stations $X, Y$, and $Z$ tracks the strain in the lower diagrams. (b) Left side - actual interseismic deformation with a locked fault, exaggerated to finite strain so one can clearly see the distortion. Horizontal lines to the left define the displacement profile perpendicular to the fault. Right - strain calculation based on the vectors at three stations. (c) Left side - static displacement after one complete earthquake cycle; right side — strain calculation from the vectors at the three stations. Note similarity in size and orientation of the ellipses on the right sides in (b) and (c). The circle experiences an increase in area from (a) to (b) to (c), because the calculation assumes homogeneous strain but the deformation is heterogeneous.

Figure 2. Two calculations of principal horizontal shortening rate magnitude from the Himalayan front in northwestern India and adjacent Nepal and China, based on data from Zhang et al. (2004). More negative shortening rates are larger. The irreg ular ellipses with four digit numbers show the extent of historic seismic rupture segments of the Himalayan front (Bilham, 2006) (a) Analysis calculated from the 15 nearest neighbors using all available stations. Note the station cluster and large negative shortening rate centered in the region of the $1400 \mathrm{AD}$ rupture. (b) Stations in the vicinity of the cluster have been randomly subsampled to produce an average density of stations more nearly similar to elsewhere along the Himalayan front.

Figure 3. Calculation of maximum horizontal interseismic shear strain rate from eastern Tibet based on data from Shen et al. (2005). The distance weighting factor $\alpha=50$ $\mathrm{km}$ and the magnitudes are in nstrain/ $\mathrm{yr}\left(10^{-9} \mathrm{yr}^{-1}\right)$. The location (red star) and focal mechanism for the 2008 Sichuan earthquake, which post-dates the GNSS data, are shown. 
Note the lack of strain anomaly in the vicinity of the earthquake, despite reasonably dense station spacing.

Figure 4. (a) Inversion of continuous GNSS data from the Plate Boundary Observatory (PBO, UNAVCO, 2008)) for 2D dilatation rate using the distance weighted approach with a weighting factor, $\alpha$, of $100 \mathrm{~km}$. This way of looking at the deformation emphasizes first order regional patterns. (b) Inversion of the same data using the 15 nearest neighboring velocity vectors to invert for strain emphasizes local anomalies. There may be other strain anomalies in the region that are not captured for lack of equally dense station spacing everywhere. In (a), the green and yellow line segments are faults $<15,000$ and $<150$ years old, respectively (from U.S. Geological Survey, et al., 2006). The red dots show the epicenters of earthquakes $M \geq 4.0$ since 1973. In (b), the black dots show the locations of the PBO stations used in the analysis. In both diagrams, units are in nstrain/ year.

Figure 5. Right lateral strike-slip fault scarp in the Chinese Parmirs $\left(39.231964^{\circ} \mathrm{N}\right.$, $74.252696^{\circ} \mathrm{W}$ ) imaged on Google Earth data, and instantaneous maximum shear strain rate planes calculated from nearby GPS stations (Zhang et al., 2004); the nearest GNSS station is $70 \mathrm{~km}$ away from this site. The green line represents the orientation of rightlateral and purple line left-lateral, instantaneous shear planes. Position of the fault along the base of the mountains and small pressure ridge suggests that the fault may have some convergence across it.

Figure 6. Coseismic deformation captured during the $1995 \mathrm{M}_{\mathrm{w}} 8.1$ Antofagasta, Chile earthquake by GPS data (Klotz et al., 1999). Red line segments show the orientations of the local principal horizontal extension rate axes and color ramp depicts magn itudes. Heavy black lines show the locations of young forearc normal faults (tick marks on the down-thrown plate) and right lateral strike-slip faults. Although new surface 
cracks formed during this event, none of these faults are known to have moved during the event (Delouis et al., 1998; González et al., 2003). Units are years ${ }^{-1}$.

Figure 7. Comparison of velocity gradient and block model analysis of the Niigata-Kobe Tectonic Zone (NKTZ) in central Japan. (a) The maximum shear strain rate from the gradient of the GEONET velocity field (Sagiya et al., 2000) reveals a northeast trending high strain rate zone (inset). A plot of contraction rate (not shown) also highlights this zone. (b) An elastic block model constrained by GEONET data estimates up to $15 \mathrm{~mm} / \mathrm{yr}$ of both dextral slip, as shown by the colored lines, and reverse slip (not shown), consistent with the deformation pattern suggested by the velocity gradient analysis.

Figure 8. (a) Interferogram (Lohman and Simons, 2005) from southern Iran spanning 21 April to 26 May 1999, showing ground deformation from a $\mathrm{M}_{\mathrm{w}} 5.3$ earthquake at $3.2 \mathrm{~km}$ depth (red region), as well as the location and focal mechanism from the Global CMT catalog (mislocated in depth by $42 \mathrm{~km}$ and horizontally by $67 \mathrm{~km}$ ) and the location in the ISC earthquake catalog (mislocated by $32 \mathrm{~km}$ in depth and $7 \mathrm{~km}$ horizontally). (b) Geologic cross section (McQuarrie, 2004) showing location and mechanism for precisely located earthquake by Lohman and Simons (2005) from (a). Black unfilled circles show earthquake located with synthetic seismograms (see references in McQuarrie, 2004), while white circles show microseismicity of Tatar et al., (2004). Courtesy Rowena Lohman. 


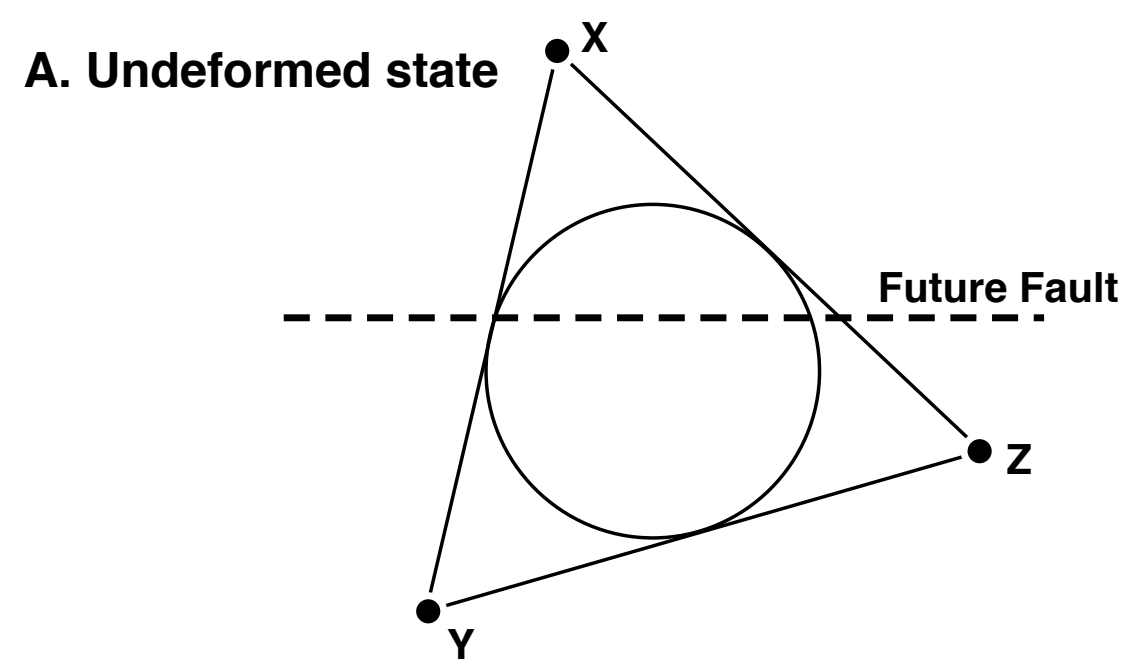

B. Interseismic deformation (heterogeneous shear zone)

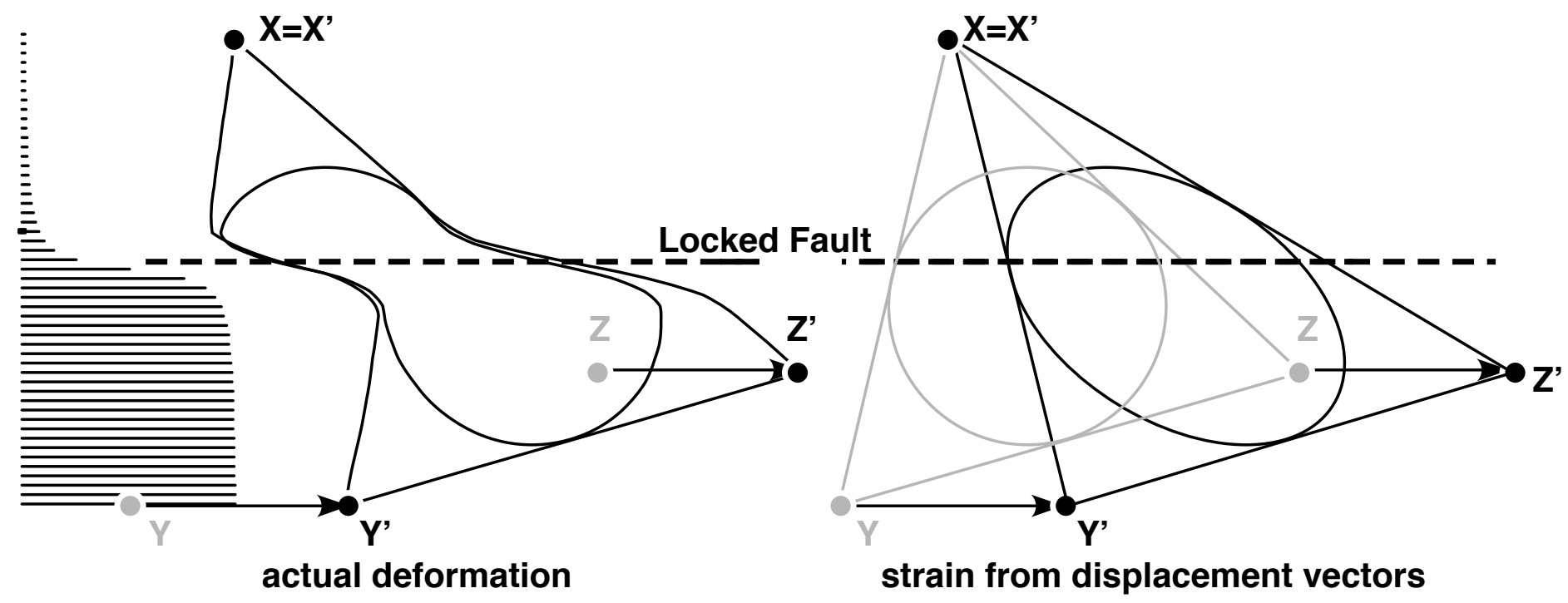

C. Static deformation after one cycle
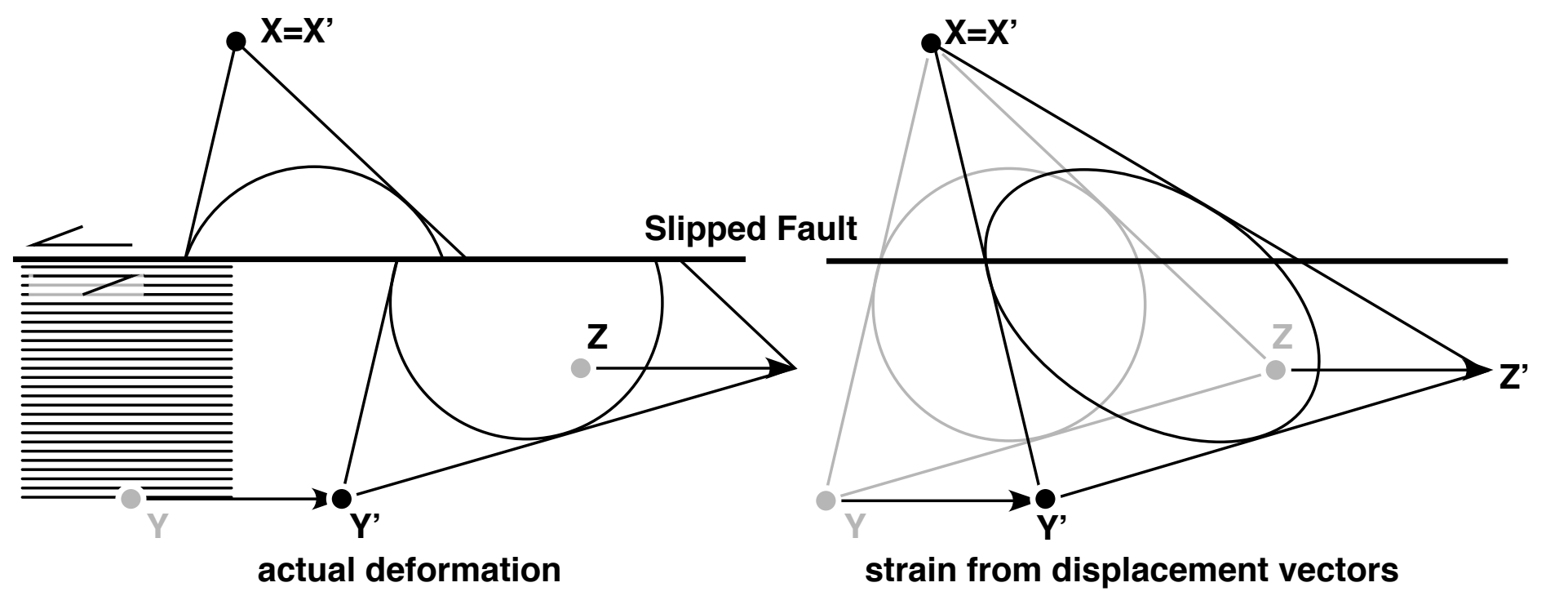

Figure 1 
Figure 2

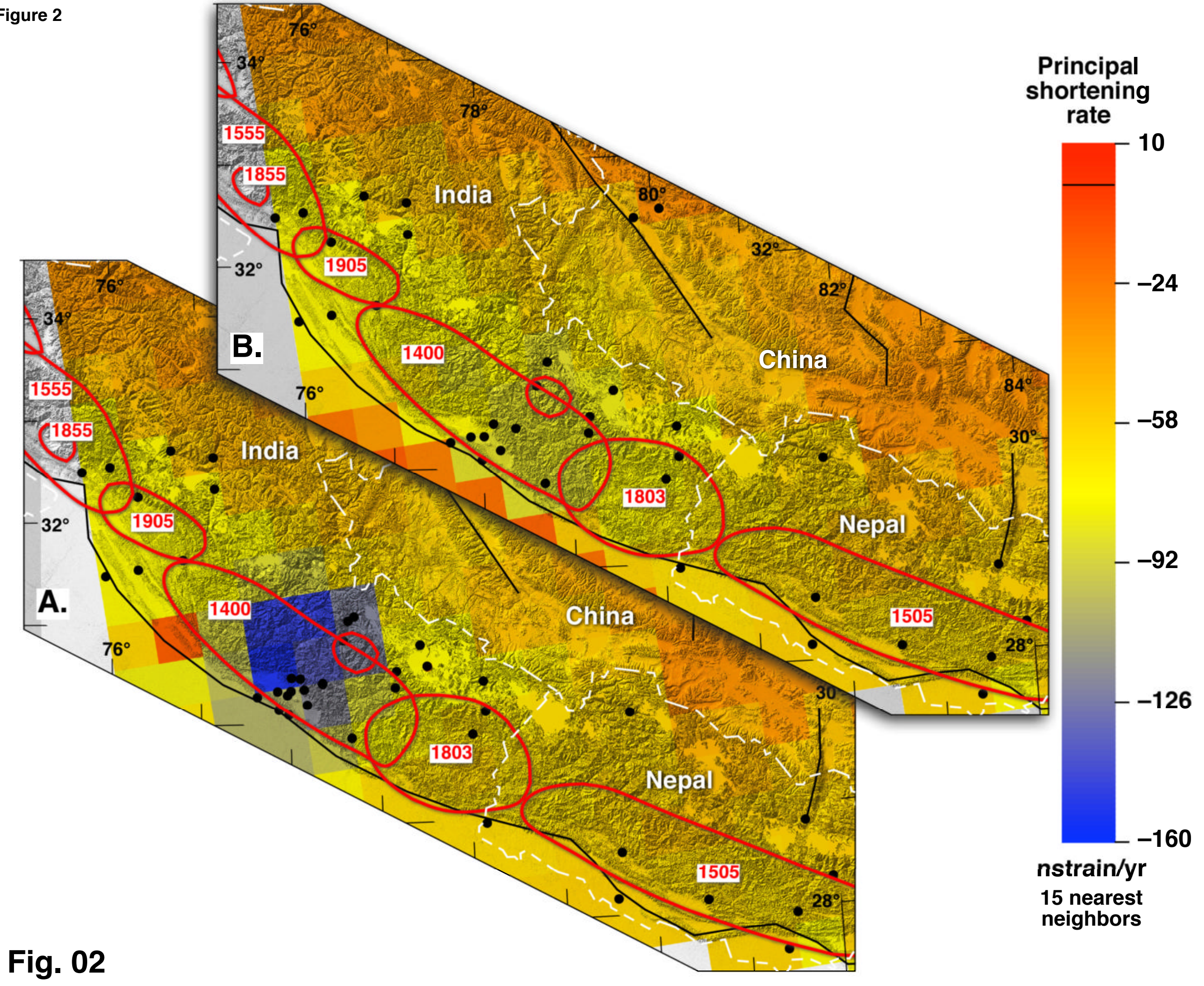

Fig. 02

15 nearest neighbors 


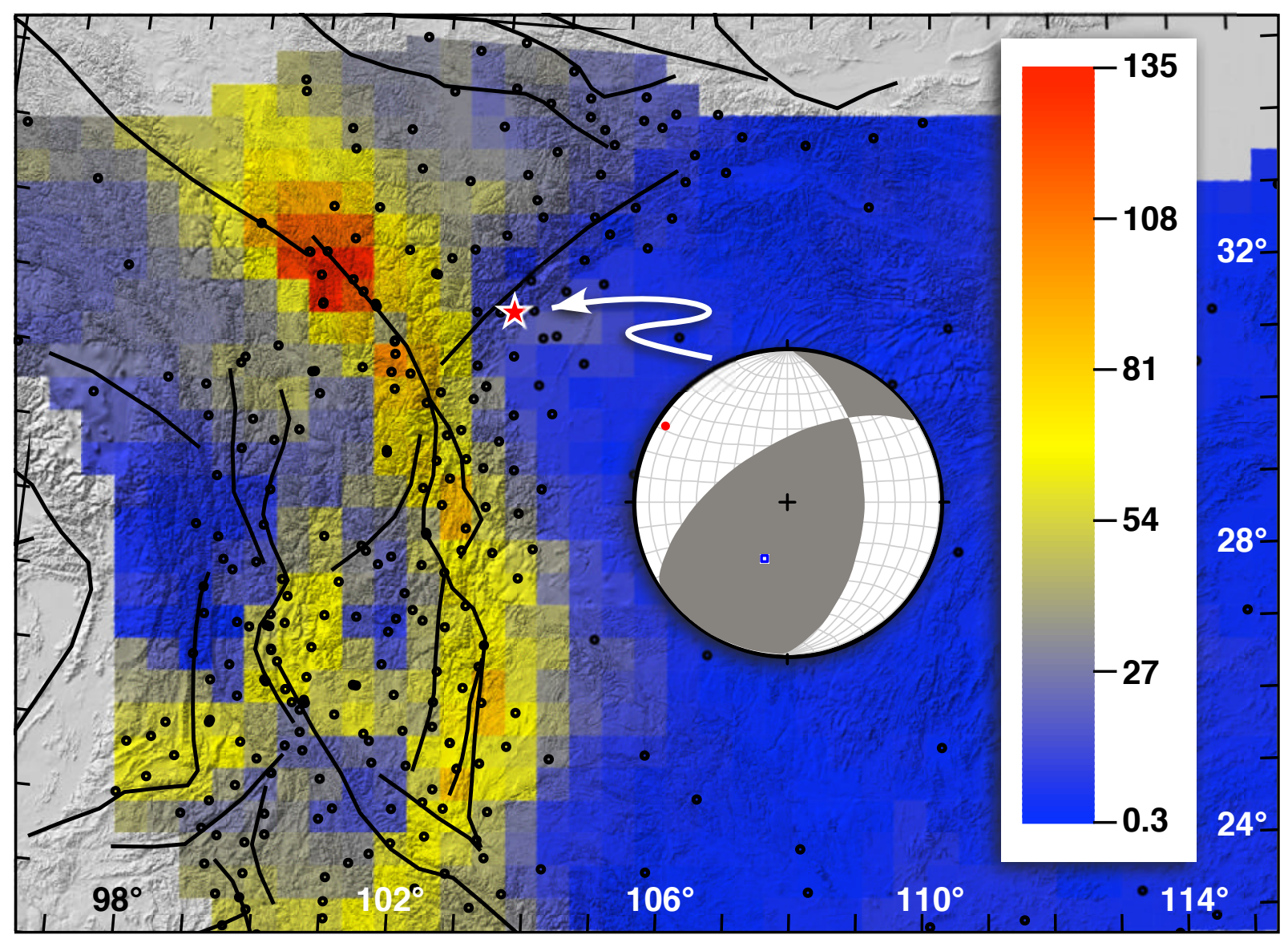

Fig. 3 

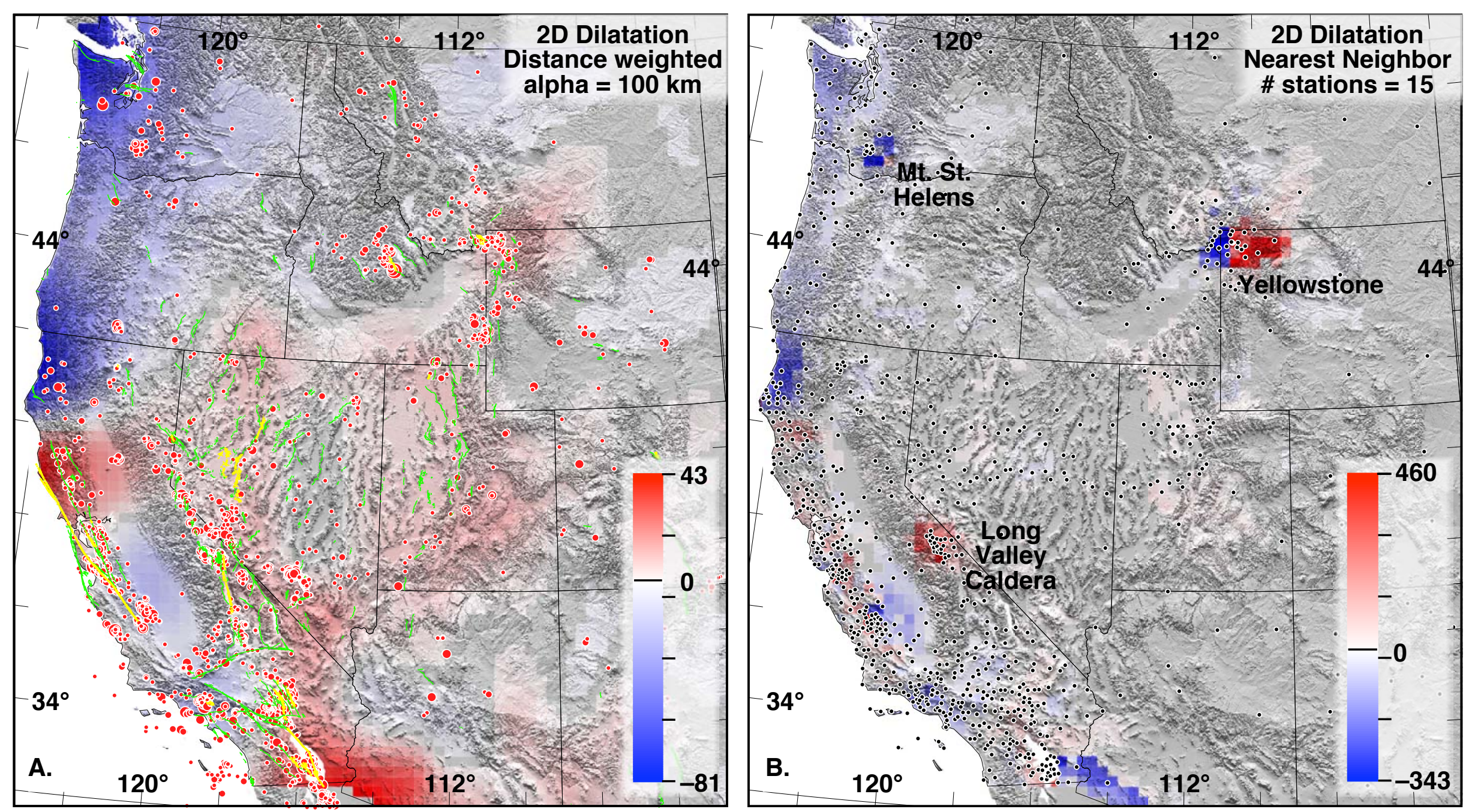

Fig. 04 


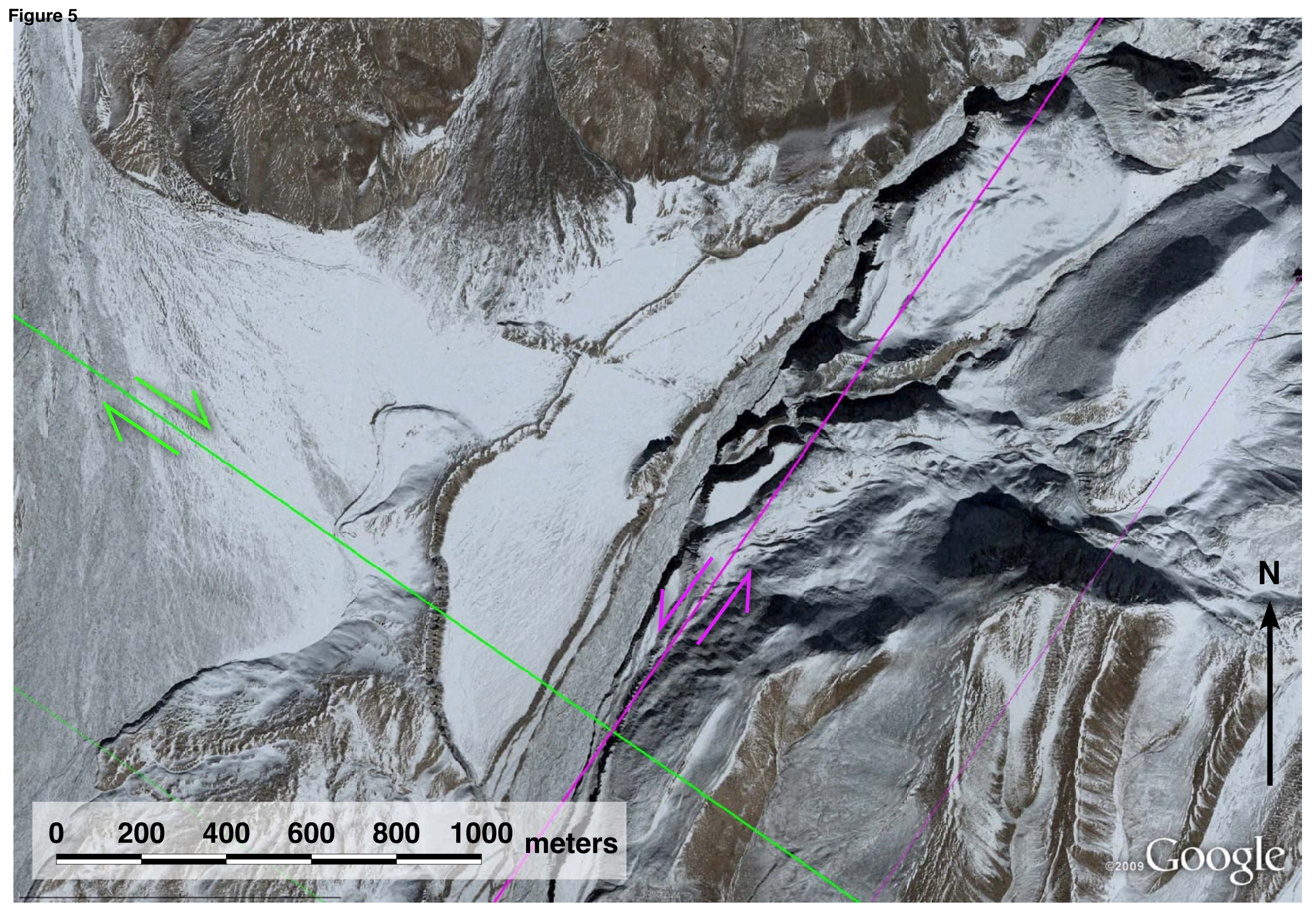

Figure 5

\section{(a)}

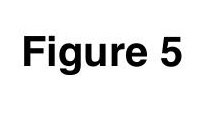

ne 


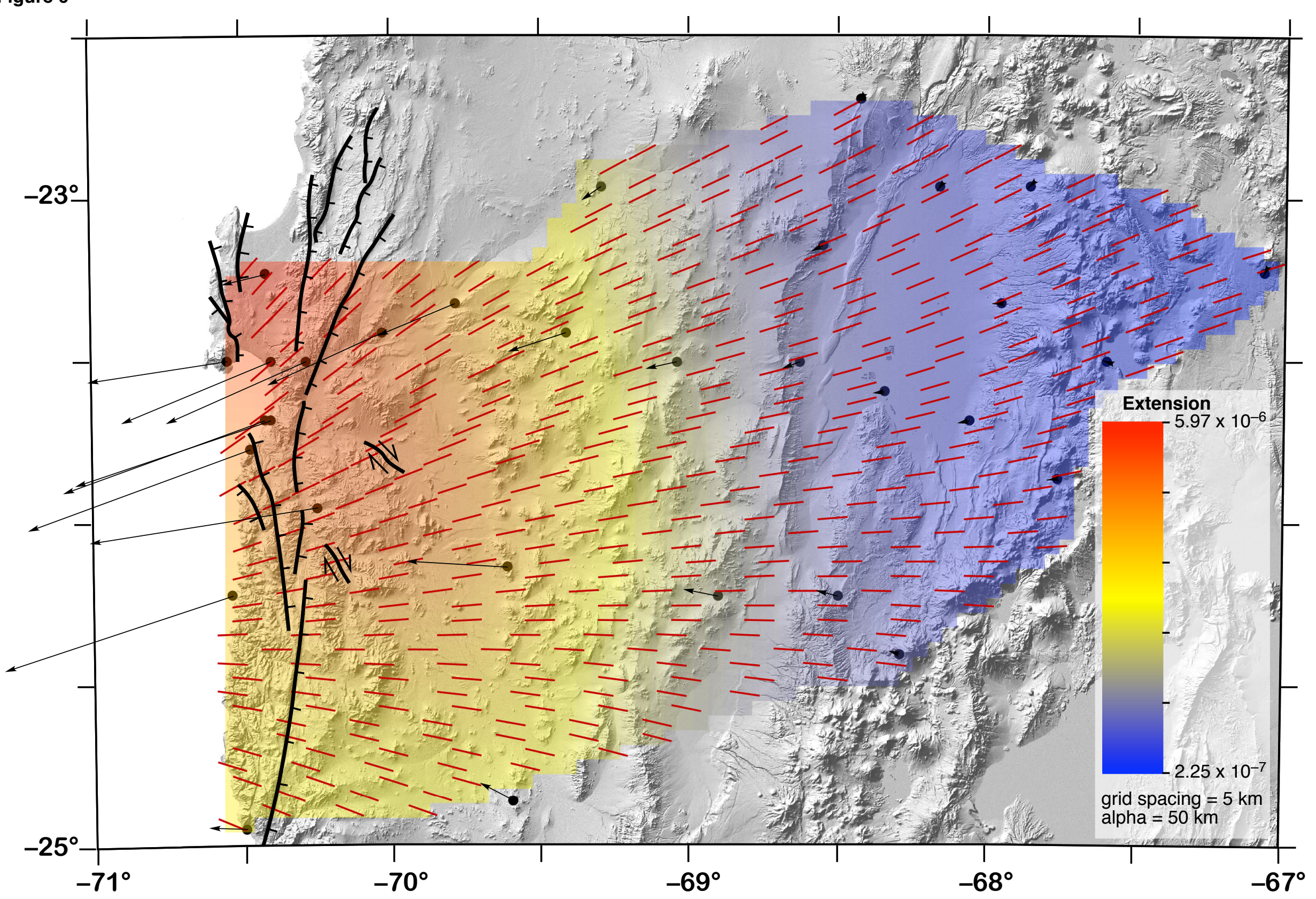

Fig. 06 



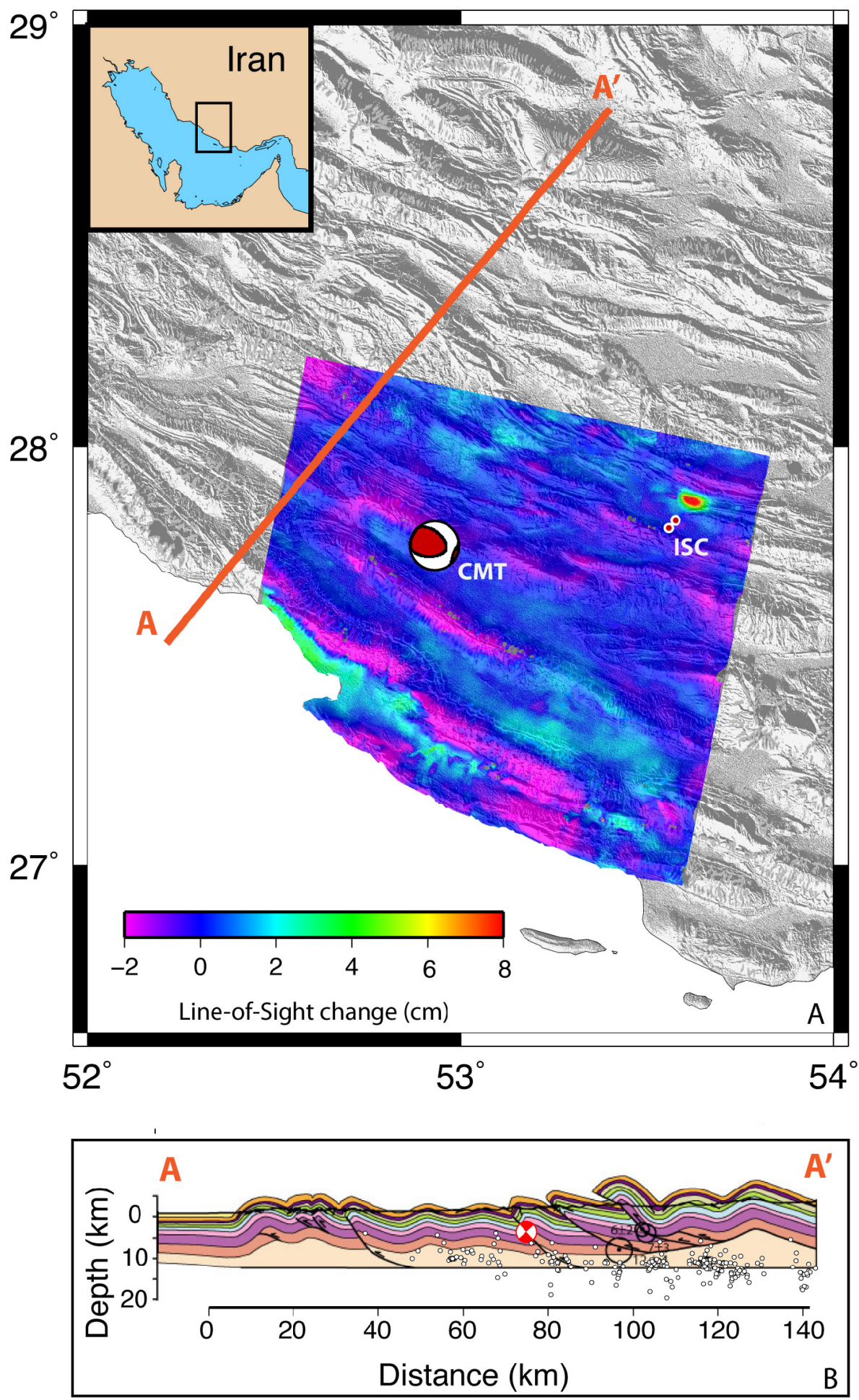

Fig. 08 